San Jose State University

SJSU ScholarWorks

Master's Theses

Master's Theses and Graduate Research

2004

\title{
Effects of computer input device on movement time and error among older adults
}

Melissa Marie Alvarado

San Jose State University

Follow this and additional works at: https://scholarworks.sjsu.edu/etd_theses

\section{Recommended Citation}

Alvarado, Melissa Marie, "Effects of computer input device on movement time and error among older adults" (2004). Master's Theses. 2536.

DOI: https://doi.org/10.31979/etd.3v67-9d5d

https://scholarworks.sjsu.edu/etd_theses/2536

This Thesis is brought to you for free and open access by the Master's Theses and Graduate Research at SJSU ScholarWorks. It has been accepted for inclusion in Master's Theses by an authorized administrator of SJSU ScholarWorks. For more information, please contact scholarworks@sjsu.edu. 


\section{NOTE TO USERS}

This reproduction is the best copy available.

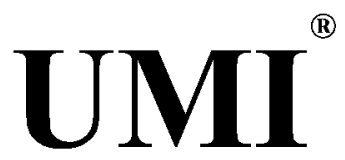



EFFECTS OF COMPUTER INPUT DEVICE ON MOVEMENT TIME AND ERROR

\title{
AMONG OLDER ADULTS
}

\author{
A Thesis \\ Presented to \\ The Faculty of the Department of Human Factors and Ergonomics \\ San Jose Sate University
}

\author{
In Partial Fulfillment \\ Of the Requirements for the Degree \\ Master of Science
}

by

Melissa Marie Alvarado

May 2004 
UMI Number: 1420418

\section{INFORMATION TO USERS}

The quality of this reproduction is dependent upon the quality of the copy submitted. Broken or indistinct print, colored or poor quality illustrations and photographs, print bleed-through, substandard margins, and improper alignment can adversely affect reproduction.

In the unlikely event that the author did not send a complete manuscript and there are missing pages, these will be noted. Also, if unauthorized copyright material had to be removed, a note will indicate the deletion.

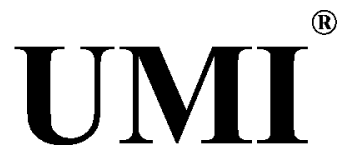

UMI Microform 1420418

Copyright 2004 by ProQuest Information and Learning Company.

All rights reserved. This microform edition is protected against unauthorized copying under Title 17, United States Code.

ProQuest Information and Learning Company 300 North Zeeb Road

P.O. Box 1346

Ann Arbor, MI 48106-1346 
(C) 2004

Melissa Marie Alvarado

ALL RIGHTS RESERVED 
APPROVED FOR THE DEPARTMENT OF

HUMAN FACTORS AND ERGONOMICS

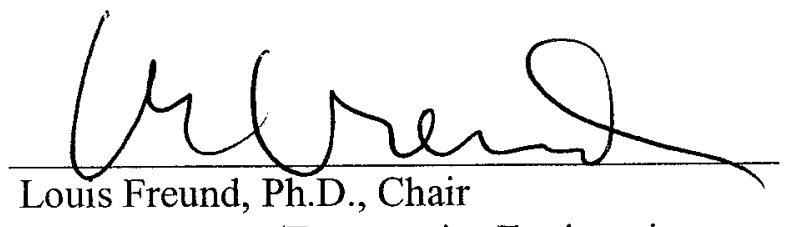

Human Factors/Ergonomics Engineering,

San Jose State University

AnOMt

Emily H. Wughalter, Ed.D., Member

Human Performance,

San Jose State University

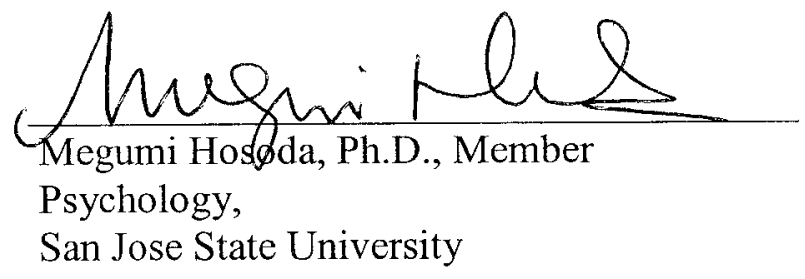

APPROVED FOR THE UNIVERSITY

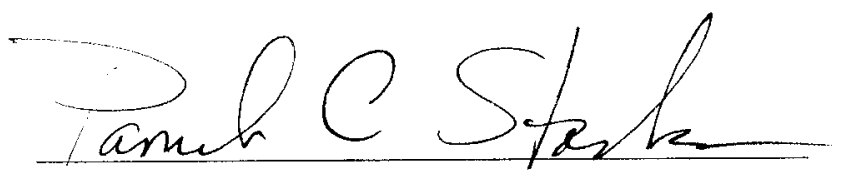




\begin{abstract}
This study investigated which computer input device a sample of adults aged 65 years and older performed best with in terms of movement time and error. Relationships between manual dexterity, computer experience, movement time, and error were examined as additional research questions. A sample of 21 older adult volunteers was interviewed to gather background information, tested with the Purdue Pegboard to measure manual dexterity, and tested on drag-and-drop and point-and-click tasks using a mouse, trackball, and graphics tablet with the Generalized Fitts' Model Builder Software. Correlation analyses and a $3 \times 2$ repeated measures ANOVA were computed with SPSS 11.5 to answer the research questions. Movement time was fastest with the mouse, followed by the graphics tablet, and then the trackball. They performed the least amount of errors using the mouse, followed by the trackball, and then the graphics tablet. No relationship was found between dexterity, computer experience, movement time, and error.
\end{abstract}




\section{ACKNOWLEDGEMENTS}

Numerous individuals have made significant contributions to this thesis project. I would like to begin by acknowledging the members of my thesis committee: Drs. Louis Freund, Emily Wughalter, and Megumi Hosoda for their knowledge, support, and commitment to my academic achievement. Dr. Freund, I have enjoyed working with you on this and other projects and look forward to continuing our professional relationship in the coming years. Dr. Wughalter, I am grateful for your insight and dedication to the success of this process. Dr. Hosoda, this study would be incomplete without your statistics expertise and moreover, I appreciate your moral support throughout the entire project.

I would also like to express my gratitude to Gordon Burton of San Jose State University who acted as a consultant to my committee and expanded the scope of my project by introducing manual dexterity concepts. I must also thank Hilary Holeman at the Mountain View Senior Center, Bonita Boren at the Life Garden Assisted Living Facility, and Kathy Alvarado, who made possible the facilitation of my study by organizing participants for my experiment sample.

Finally, I would like to acknowledge the friends and family who have stretched my imagination and helped to keep me motivated throughout this learning process. My

mother has been a continual source of experience and support thought this and my entire educational life. Thank you for helping me to realize the splendor of growth and perseverance. 


\section{TABLE OF CONTENTS}

SECTION

Introduction. 1

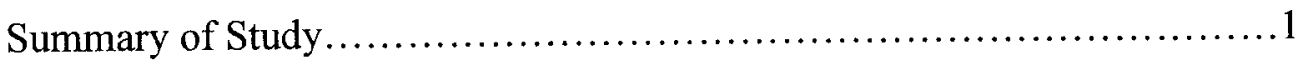

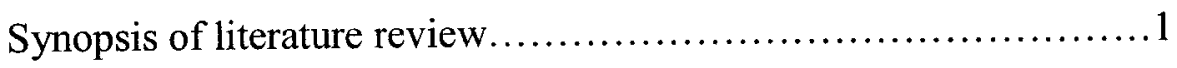

Significance of the study......................................2

Delimitations...............................................

Limitations..............................................

Proposed research questions................................... 5

Definition of terms................................................. 6

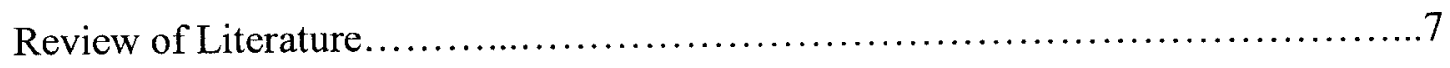

Age and computer-use trends in America................................

Older adults' attitudes towards computers $\ldots \ldots \ldots \ldots \ldots \ldots \ldots \ldots \ldots \ldots \ldots \ldots$

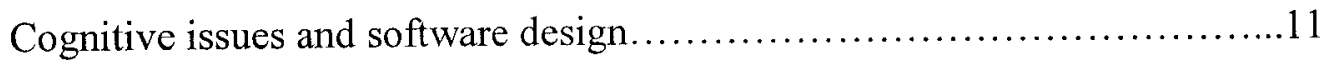

Physical issues and hardware design................................. 12

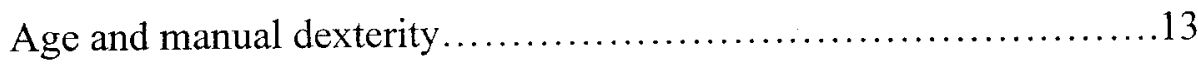

Age and computer input device performance $\ldots \ldots \ldots \ldots \ldots \ldots \ldots \ldots \ldots$

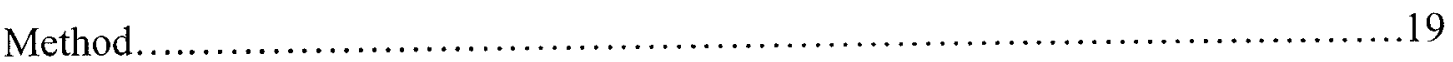

Instrument and Apparatus......................................... 19

Software............................................... 19

Computer system configuration..............................20

Input devices............................................. 20 


\section{TABLE OF CONTENTS}

SECTION

Dexterity measurement device....................................24

Participants...........................................................24

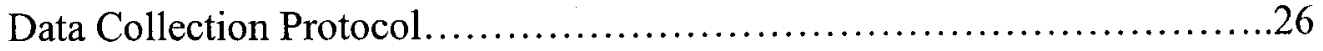

Configuration of data collection...................................26

Configuration of devices.......................................28

Experiment procedures..........................................28

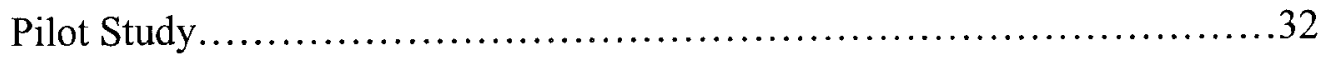

Research Design.......................................................... 34

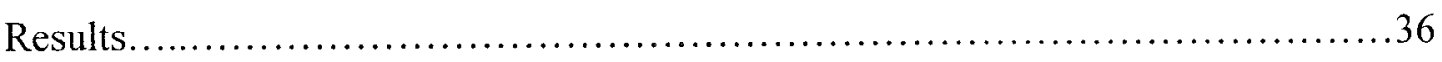

Descriptive Statistics................................................

Pearson Correlation.................................................... 38

Repeated Measures ANOVA ..........................................43

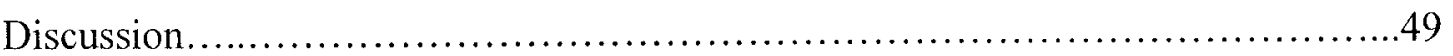

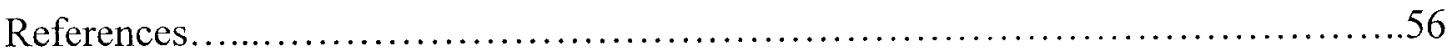

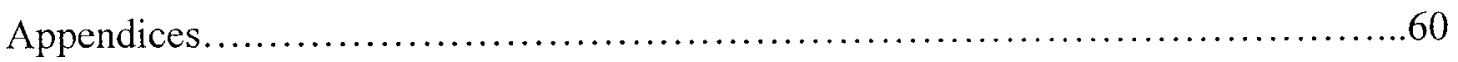

Appendix A. Human Subjects-Institutional Review Board Approval Letter...60 Appendix B Participant Consent Form................................61

Appendix C Demographics Questionnaire .............................63

Appendix D Purdue Pegboard Manual..................................66

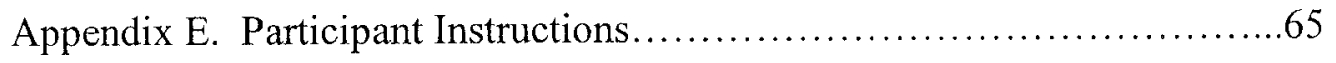




\section{LIST OF TABLES}

TABLE

PAGE

1. Order of Device and Task Type Presentation............................ 31

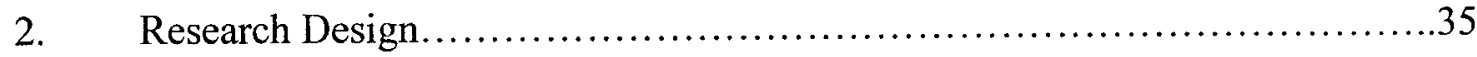

3. Descriptive Statistics of Demographic Variables......................... 37

4. Purdue Pegboard Dexterity Data.........................................

5. Pearson Correlations................................................... 42

6. ANOVA Summary Table for Movement Time.........................44

7. ANOVA Summary Table for Error................................. 47 


\section{LIST OF FIGURES}

FIGURE

PAGE

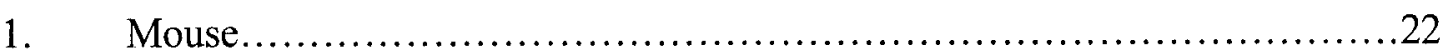

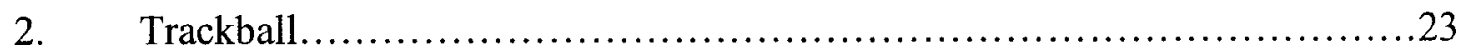

3. Graphics Tablet with Digital Pen......................................25

4. Annotated Screen Shot of GFLMB Software with Terms Used in

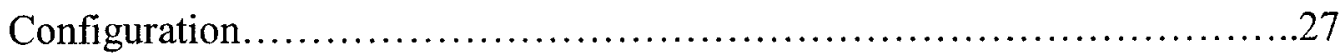

5. Annotated Screen Shot Illustration of Main Test..............................33

6. Mean Movement Times in Milliseconds for each Task Type and

Device Type Combination..............................................45

7. Mean Error for each Task Type and Device Type Combination.................48 


\section{Introduction}

\section{Summary of Study}

Synopsis of literature review. The "Graying of America" is a term given to the phenomenon that the country's population over age 65 years is continuing to grow. According to the US Census Bureau (2000), the percentage of people in this age group tripled from 1990 to 1997 . By the year 2030, an estimated 20\% of America's population will be "gray."

The US Census Bureau (Newburger, 2001) also reports an increase in the use of home computers and the Internet. From 1997 to 2000, the percentage of American households with computer Internet access more than doubled to $42 \%$. This means that almost half of America is on-line with their computers. Why is it then that less than one third of the older adult population (age 65 years and older) is using a computer at home? Of the possible answers to this question, the physical demands of using a computer were investigated in this study.

It is common for computers to be controlled by an input device that is manipulated by the user's hand; probably the most familiar is the mouse. Other alternatives are also available such as the trackball, touch screen, and the graphics tablet used with a digital pen. The mouse is the most familiar because it is generally included as one of the components when purchasing a complete computer system, but perhaps it is not the best input device for everyone.

Previous research on computer user performance includes studies that have varied the type of devices used but not considered the age of the user (Card, English \& 
Burr, 1978; Card, Moran \& Newell, 1983; Hancock, 1996; Harvey \& Peper, 1997; Karat, McDonald \& Anderson, 1986; Sears \& Schneiderman, 1991). The results of these studies point to particular devices as being superior in terms of a certain task. Other studies have varied the age of the user but tested performance of only one device (Chaparro et al., 1999; Hutchinson et al., 1997; Smith et al., 1999). In general, these studies have exhibited age-related differences in that older age groups perform at a lower level than the younger age groups. In addition, numerous studies exist indicating agerelated declines in fine motor control (Desrosiers et al., 1999; Galanski, Fuglevand \& Maenoka, 1993; Houx \& Jolles, 1993; Light \& Spirudoso, 1990; Smith et al., 1999), with few pertaining to computer performance in particular (Smith, Sharit \& Czaja, 1999).

The present study examined computer input device performance by a group of people from a specific age group, 65 years and older. Each participant's manual dexterity was measured and rated according to normative data for the population. Ultimately dexterity, and movement times and errors using three different computer input devices (mouse, trackball, and graphics tablet with digital pen) were evaluated to determine the device that was most effective (i.e., the device with which they produced the shortest movement times and fewest errors) for people in this age group.

Significance of the study. The older population's attitude towards computers is not consistently positive. Results of a study by Czaja and Sharit (1998) indicated agerelated differences for computer attitudes. Older users reported less comfort and competence, and reported that they had less control over computers than younger users. 
The present study was designed to identify the most effective input device in terms of movement time and error for a group of seniors 65 years and older. If a particular device can be determined and implemented for this population, then perhaps the aforementioned attitudes of older adults might improve, encouraging them to continue and expand their computer use.

Results of this study may not only benefit the older computer user by making their computer experience more effective and enjoyable, but may also aid in the marketing efforts of peripheral device manufacturers. If it is found that people age 65 years and older perform better with a particular device, then they could be considered a target market for that device. Specific marketing campaigns directed towards the older adult computer user population could potentially be developed based on the findings of this study.

Delimitations. The age of the participants was limited to 65 years and older. Also, this study only admitted participants who declared themselves right-handed in terms of using a computer input device. This was to ensure equal usability of the mouse, trackball, and graphic tablet across participants. The nature of the mouse and graphics tablet is such that they may be used with either the left or right hand, although the particular trackball used in this study is strictly designed for use with the right hand.

This study only admitted participants who had no recent injuries to their right hand, wrist, arm or shoulder, and who had no hand or arm-related diseases such as tendonitis, carpal tunnel syndrome, or epicondylitis. Because arthritis is common among people age 65 and older, participants with arthritis were included in the study given that 
they were comfortable with the procedure. Excluding possible participants based on these criteria helps to ensure that the manual dexterity measured with the Purdue Pegboard was a valid measure of participants' natural dexterity, not influenced by factors beyond those occurring with age. Participants were not excluded due to visual limitations given that they used corrective lenses and were comfortable with the procedure. The primary language of the participants was limited to English. The written instructions and consent form were presented in English, so controlling for primary language may have aided in the participants' understanding of their role in the study.

The level of experience of the participants was controlled and limited to people with at least 20 hours of computer experience with a Windows-based operating system. Controlling this variable assumed that the participants had an understanding of the indirect nature of the input device; that is, the task of controlling what they were viewing without touching the screen was not novel.

The scope of the study was set by choosing three computer input devices: a mouse, a trackball, and a graphics tablet. More types of devices exist, but these three were chosen because they are some of the most common in a group of devices that are manipulated by a participant's hand.

The actual tasks that were tested were pointing-and-clicking and dragging-anddropping tasks configured with the Generalized Fitts' Law Model Builder Software. The software measured the movement times and errors of the participants for each task trial. Most computer activities are based on these simple controls (i.e., drag-drop and pointclick) of the input device. If it can be shown that a user performs better on these tasks 
with a certain device, it can be assumed that the user will perform better on everyday computer activities using that same device.

Limitations. Due to practicality restrictions, the method of sampling was not random. This may limit the external validity of the results in that the sample tested may not be truly representative of the entire population of Americans age 65 years and older. The Hawthorne effect may have hindered the internal validity in that participants may have performed differently than they would have normally, simply because they were receiving attention by being included in the experiment.

Because each of the participants performed the tasks with all three devices, practice effects might have impeded the internal validity of the study. In an attempt to protect against this source of invalidity, results from a pilot study determined the number of trials necessary before participants reached a consistent movement time with each device. During the actual data collection session, each participant was given a practice interval and allowed to repeat it if needed. The data collected after this practice interval were used in analysis. In an attempt to protect against carry over effects, the orders of task type presented and input device used were counterbalanced across the study.

Proposed research questions. How does input device affect the movement time and error among computer users age 65 and older? How does task type affect the movement time and error among computer users age 65 and older? How does the interaction of input device and task type affect the movement time and error among computer users age 65 and older? Is there a relationship between manual dexterity, 
length of previous experience, movement time, and error in computer tasks performed by adults aged 65 years and older?

Definition of Terms

Dexterity. Dexterity is a measure of the skill of using one's hands; the ability to manipulate objects with the hands.

Error. For this project, an error is an instance during a test trial when the participant attempts to end the trial but does not have the cursor inside the target. The number of errors a participant makes during a particular set of trials (as counted by The Generalized Fitts' Law Model Builder Software) is called the error count.

Fitts' Law. Developed in 1954, Fitts' Law is a model of human psychomotor behavior based on time and distance. Movement time is a logarithmic function of distance when target size is held constant and movement time is a logarithmic function of target size when distance is held constant.

Graphics tablet with digital pen. The graphics tablet is a computer input device that resembles a writing surface and a pen with which the user moves the cursor and makes selections in the same manner as writing with a pen.

Mouse. The mouse is a computer input device that rests on a surface beneath a user's hand and is manipulated by the user moving their hand (movement initiated from the shoulder and back) and making selections using their first finger.

Movement time. Movement time is the time in milliseconds (as counted by The Generalized Fitts' Law Model Builder Software) from the beginning to the end of one 
trial. Movement times used for statistical analysis are averages for a set of trials. Movement time does not include reaction time because the user self-initiates the trial. Older adult. For this study, an older adult is considered to be a person 65 years old or older.

Trackball. The trackball is a computer input device that remains stationary on a surface beneath a participant's hand and is manipulated by the partcipant moving their thumb over a ball (movement initiated from hand/forearm) and making selections with their first finger.

\section{Review of Literature}

Age and computer-use trends in America

Due to increased life expectancy and declining fertility, the percentage of older adults in America is increasing (Starr, 1999). The U.S. Census Bureau (2000) reported that the percentage of people age 65 years and older tripled from 1990 to 1997, while the actual numbers grew from 3.1 million to 34.1 million that time. The Census Bureau estimates that while 12.76 percent of the U.S. population was 65 and older in 1995, by the year 2030,20\% of America's population will reside in this older age group.

In conjunction with this growth trend is the rise of computer use. In 1997 the U.S. Census Bureau began collecting data regarding the use of computers in people's homes. Over the three years from 1997 to 2000 , the percentage of households with at least one person using a home computer and the Internet more than doubled to $42 \%$, an equivalent of forty-four million households (Newburger, 2001). 
Because both computer use and the population of older adults are growing, it would seem to follow that the percentage of older adults using computers would also be on the rise. Unfortunately, the trend may not be that simple. The use of home computers in the year 2000 was reported according to age group, and the percentage of users age 65 years and older was less than any other age groups. Only $24 \%$ percent of the total households aged 65 years and older reported having a computer in their home and only $17 \%$ of these total older adult households reported having Internet access (U.S. census Bureau, 2001).

The statistics regarding the older adult population and computer use cannot be ignored. Developments in computer and networking technology have made it possible for people to access large amounts of information from home using the Internet, however if older adults are not using computers, they cannot take advantage of this vast network of information. Services that may be of special interest to older adults include electronic mail, databases containing health-related information, on-line pharmacies and general shopping, entertainment, and news. It is not to say that they will not survive without using computers and the Internet, but the successful adoption of this sort of technology is becoming increasingly important to a person's ability to live and function effectively within society (Czaja \& Sharit, 1998).

\section{Older adults' attitudes towards computers}

The lack of computer involvement among older adults is not necessarily the fault of the user, however. The needs of this age group have been virtually ignored by interface advances. It seems that rather than compromising the features of interfaces for 
the general population, developers have implicitly chosen to disregard the physical limitations of older adults (Hutchinson, Eastman, \& Tirrito, 1997).

Whether it is due to the lack of consideration by designers or the lack of personal interest of these older users, reports of their attitudes do not exhibit an overall positive feeling about using computers. According to Elias, Elias, Robbins, and Gage (1987), older users are afraid of damaging the computer hardware and software. They perceive that the system is fragile, which causes them to experience a high level of anxiety when working with it. Older adults tend to blame themselves when something goes wrong with the computer (Zandri \& Charness, 1989). This makes them less likely to experiment with different features for fear that a disaster may result. In particular, Kerschner and Hart (1984) suggested that $50 \%$ of older adults feel that computers are too confusing to be worth their attention or effort.

Czaja and Sharit (1998) examined age differences in attitudes towards computers as a function of experience with computers and computer task characteristics. The participants, ages ranged from 20-75 years old, performed real world computer tasks for a three-day period. Their attitudes were assessed before and after the experience interval, using a multidimensional computer attitude scale. Their findings indicated that both before and after the experience period, older people reported less comfort and competence (comfort and competence were two of the dimensions of attitude measured in the study) with computers and that they had less control over them, as compared to the younger participants. Older adults also perceived computers to be more dehumanizing (another measured dimension of attitude) than did the younger participants. Although 
older adults reported unpleasant attitudes regarding these dimensions in particular, the study did not find any significant age effects for overall attitude (all attitude dimensions combined) either before of after the experience period. The results ultimately suggested that irrespective of age, direct experience with computers resulted in a more positive attitude.

Dyck and Smither (1994), and Jay and Willis (1992) have reported similar results. They found that for all the age groups included in their studies, a higher level of computer experience was associated with lower levels of computer anxiety, and hence better attitudes towards using computers. Specifically with the older participants, improvement in attitude following direct experience was found on two dimensions: computer efficacy and comfort (Jay \& Willis, 1992).

Contrary to these findings, one study suggested that age is s not related to reservations with respect to new technologies (Marquie, Thon, \& Baracat, 1994). These findings, however, were based on the technology of credit card machines used at the pump at a gas station, not necessarily personal computer use. Similarly, Edwards and Englehardt (1989) suggested that older adults have generally positive attitudes towards computer technology. Results of their questionnaire-based study indicate that overall, older adults believe that computers made living in society easier and that one has to understand computers in order "to make it in the world today." A possible explanation for these differences in results may be due to the time frame of the study in question. The rapid changes in computer technology in the last decade may have some impact on the changes in people's attitudes towards using them. Perhaps, older adults used to feel that 
they could interact with the machines, but because computers continue to expand in their capabilities, they may feel too overwhelmed to be a part of such a system.

Nevertheless, the most currently published results seem to indicate that people's attitudes improve following direct experience with computers. If the goal is to make people feel better about using computers, attention should be directed at increasing their exposure and experience (Kelley, Morrell, Park, \& Mayhorn, 1999).

The next question then should be as to how to increase their exposure and experience. What design issues should be considered to make computer use more desirable for older adults? Interaction with a computer involves both cognitive and physical functions of the user. The cognitive issues pertain more to the software development, whereas the physical issues are considered in the design of the hardware. Cognitive issues and software design

The natural degradation of people's cognitive system as they age can have negative effects on their use of computers. Some of the characteristics that are of concern include vision, memory, learning, and attention (Birren \& Schaie, 1990).

Fozard (1990) suggested that in their early forties people begin to experience certain problems with vision. At this stage, adjusting focus for near vision becomes more difficult and the visual acuity, the ability to see fine detail, declines. Contrast sensitivity, which is another aspect of visual acuity, also declines from age 20 to age 50 , and significantly again by 80 years old (Owsely, Sekuler, \& Siemsen, 1983). Based on these age-related changes in vision, Hawthorn (2000) recommended that the overall layout of the computer software interaction be simple, clear, and concise. He also suggested using 
extra, bold-type search cues. Laux (2001) added to these ideas by indicating the use of only a few colors and sans-serif fonts of at least 12-point font size.

Older adults experience decrements in their working memory that may interfere with their ability to use computers (Laux, 2001). These deficiencies may make it difficult for them to retain information long enough to act on it and to transfer knowledge from long-term memory to working memory (Charness, Park, \&Sabel, 2001). Hawthorne (2000) summarized some design implications and suggested that benefits for older people are possible by reducing the interface demands on working memory. Emphasizing the simplicity of design and avoiding distractions and unnecessary manipulations can help achieve this goal. Interfaces should allow users to process concrete representations of items rather than relying solely on working memory. Findings from a survey-based study (Hutchinson, Eastman, \& Tirrito, 1997) recommended the use of an involuntary help window, which is present on the screen at all times, describing the screen's contents and explaining possible actions for the user. The purpose of this design is to help the older user through the learning process by reducing the memory recall demands.

The ability to divide attention and to ignore irrelevant stimuli also diminishes with age (Hartley, 1992). This may cause problems if older computer users must attend to multiple stimuli simultaneously, especially if some of the stimuli are very demanding of the user's attention (i.e., with a blinking or beeping accompaniment). Laux (2001) suggested only using elements that compete for the user's attention when the intended goal is to distract the user as in the case of a warning or alarm. She also discouraged the simultaneous use of conflicting visual or audio information. 
Physical issues and hardware design

Although there may be room for improvement in the design of computer software, the cognitive interaction with computers is not the only area that can be refined. Recalling that the goal is to increase the older adult population's exposure to and experience with computers, there is another facet of interaction to be considered. Most computers are controlled with a manual input device such as a mouse. The tasks required, such as pointing and clicking on an object on the screen or dragging and dropping an icon to another location on the screen, demand the user's fine motor control and may be more difficult for older adults (Smith, Sharit, \& Czaja, 1999).

Age and manual dexterity. Out of the context of the computer environment, age effects on fine motor control have been examined. Smith et al. (1999) compared fine and coarse motor performance times between adult groups (average age of 34 years) and aged groups (average age of 76 years). They reported an effect of age on both fine and coarse motor performance, with the aged group demonstrating longer movement times than the younger adult group. Overall, fine motor performance time was significantly longer than coarse motor time. Similarly, Houx and Jolles (1993) found an age-related slowing in the motor execution times of a task involving holding a button in an activated position until a stimulus was presented and then reversing the pattern as directed by the state of the stimulus.

Light and Spirduso (1990) suggested that reaction times are longer for an older group (age 60-70) than a middle aged (40-50 years) and a young (20-30 years) group. They also reported that these differences increased as movement complexity increased. 
Their study involved tasks in which the participants manipulated micro switches with their thumb and forefinger as directed by a light stimulus. The results indicated that the older subjects were more sensitive to small changes in movement complexity than were the middle aged or the young group.

In a longitudinal study performed by Desrosiers et al. (1999), healthy older (age 60 and older) people's upper extremity performance levels were measured at an initial time and also three years later. One of the measurements recorded and analyzed was fine manual dexterity. It was measured using the Purdue Pegboard test. This test consists of manipulating small pins on a board as quickly as possible in a timed period. The score is the number of pins handled, with a higher score indicating a better performance. Results of their study indicated a significant decrease in the participants' performance over the three years. These findings suggest that unimpaired older adults suffer from a loss in their manual dexterity over time.

These examples provide support for the idea that along with aging comes degradation in performance associated with fine motor control tasks, but also worth considering are the actual physical changes of the aging body. Stubbs, Fernandez, and Glenn (1993) reported a $16 \%$ reduction in the available maximum range of motion for the wrist between the age ranges 25-34 and 45-54. This finding implies that if such a reduction in range of motion were present for these age ranges, then the reduction would be even greater for older people (Chaparro, Bohan, Fernandez, Choi, \& Kattel, 1999).

Further investigating the age differences in fine motor control of the hands, Galganski, Fuglevand, and Maenoka (1993) conducted a study involving three tasks 
(maximum voluntary contraction, constant force, and threshold) that required isometric abduction of the left index finger. Their reports indicated that the ability of older adult participants (60-75 years) to control muscle force during the constant-force task was lower than that of the younger participants (20-37 years).

Handwriting is a practical application of manual fine motor control. Differences in handwriting production for older individuals have been demonstrated by the results of several studies. For example, Vidal, Teulings, and Stelmach (1998) conducted a study in which young and old participants performed handwriting tasks on a digitizer-display connected to a computer. The participants made a series of back and forth strokes in a set variety of angles. Their results suggested that the spatial coordination of finger and wrist movements during handwriting among older adults was degraded as reflected by their larger errors in oblique strokes.

While there are numerous studies that have indicated age-related declines in fine motor control, little data are available as to its impact on the use of computer input devices. Some studies have examined age differences in performance of using a single input device, where others have considered the effects of different types of devices on performance across age groups.

Age and computer input device performance. Regardless of device (mouse or trackball), older participants exhibited slower movement times than younger participants on a series of point-and-click and drag-and-drop tasks (Chaparro et al., 1999). The results of a study by Smith et al. (1999) support these findings in that older participants experienced more difficulty with clicking and double-clicking tasks than the younger 
ones. This finding is evidenced by longer movement times, more sub-movements, and more errors made by the older group. Specifically, the double-clicking task was the most sensitive to age effects.

Smith et al. (1999) suggest that their data provide evidence that age-related declines in motor control are related to age differences in computer mouse performance. The older adults made more slip errors that were related to their ability to home in on the target. The link suggested by Smith et al. is that manual dexterity was a strong predictor of slip errors because the older adult participants in the study had lower manual dexterity than the others. The task associated with the most errors for all of the participants was the double-clicking task. The problem that older adults tended to have with this task was their inability to simultaneously hold the mouse still and rapidly push the button.

Results of a survey of computer users age 50 and older indicated that $27 \%$ of older adult users have difficulty using the mouse as a computer input device (Hutchinson et al., 1997). Specifically the users described their experiences of "aiming the pointer at small buttons, clicking the mouse and then waiting while nothing happened." They eventually realized that they had missed the target and retried as many as two to three times. One participant specifically reported "he could not click the mouse button without slightly moving it."

To expand the scope of research on performance with computer input devices, several studies have examined differences associated with using different types of devices, regardless of the age of the user. The types of input devices commonly used have evolved over time. In 1978, Card, English, and Burr reported their results of a study 
examining performance difference between a mouse, an isometric joystick, step keys, and text keys. At that time, the mean movement time for the tasks was fastest with the mouse. Similarly, Card, Moran, and Newell (1983) found that the mouse had the least errors associated with it, in comparison again with the joystick, step keys, and text keys. Karat, McDonald, and Anderson (1986), and Sears and Schneiderman (1991) expanded the field of devices to include a touch screen. The results of both studies suggested that the touch screen is a better menu-selection device than the mouse. It is questionable, however, to compare a touch screen with a mouse due to the nature of each device. The touch screen is a direct input device where the user actually touches the selection viewed on the screen. On the other hand, the mouse acts as an indirect input device in that the user moves a cursor on the screen by manipulating their hand on a different surface (i.e., the mouse pad).

At the present time, it is more common to use a mouse than a keypad or joystick and even a touch screen for home computer use (however, the touch screen is prevalent in other types of intelligent interfaces like ATM's). In addition, however, there are other devices that are readily available such as the trackball or the digital pen used in conjunction with a graphics tablet. Due to the relative novelty of these devices, fewer studies have been conducted on a user's performance with them.

As a result of Hancock's (1996) study of performance on a tracking task with a trackball and a mouse, it was reported that "performance with the trackball was clearly superior to that with the mouse." The author indicated that trackball use resulted in more accurate performance and was judged to be of lower subjective workload than input 
using the mouse. Similarly, Harvey and Peper (1997) reported superior performance with the trackball over the mouse. They also ranked the trackball higher than the mouse in terms of decreased muscle tension. Using the mouse to the right of the keyboard led to a significant increase in muscle tension in the upper shoulder, back and arm, however significantly lower muscle tension was observed with the trackball used in a central position.

The results of these studies suggest that the trackball is the better computer input device but Baber (1997) reported contradictory findings. He suggested that performance time on computer input tasks was faster for the mouse (and the touch screen) than the trackball. While there are seemingly very few studies including the trackball as a computer input device, even fewer are the studies investigating the digital pen.

Because it appears that no consensus has been reached as to which computer input device is better for any given user, it is not surprising that it remains unknown which device is best for older adults. Chaparro et al. (1999) reported that both young and old age groups were slower with the mouse than the trackball. They further said that in terms of performance the older group showed no differences on performance between the two devices, and finally, on the basis of user preference, they reported that older adults preferred the trackball to the mouse. From these results, it appears that the trackball seems to be the best choice for older users. Not only did they perform better with it but also they actually prefer using it to the mouse.

Due to the lack of research in the area of older adult computer users and input devices, the purpose of this study was to explore older adults' performance with a mouse, 
a trackball, or a digital pen with graphic tablet. The following research questions were tested: How does an input device affect the movement time and error among computer users age 65 and older? How does a task type affect the movement time and error among computer users age 65 and older? How does the interaction of the input device and the task type affect the movement time and error among computer users age 65 and older? In addition, this study examined a possible relationship between manual dexterity, length of experience, movement time, and error in computer tasks performed by adults aged 65 years and older.

\section{Method}

In this experiment differences in movement time and error on pointing-andclicking and dragging-and-dropping tasks with different computer input devices by older adult users was studied. The Generalized Fitts' Law Model Builder software recorded movement times and errors made by the participants using a mouse, trackball, and graphics tablet. The Purdue Pegboard was used to measure the manual dexterity of each participant. The relationships between dexterity, computer experience, movement time, and error, and the differences in movement time and error were analyzed with SPSS 11.5 for statistical and practical significance.

\section{Instrument and Apparatus}

Software. The study was conducted using Generalized Fitts' Law Model Builder (Soukoreff \& MacKenzie, 1995). It was run on a personal computer with an appropriate graphical display and a selection input device (i.e., mouse, trackball, graphics tablet). The creators of Generalized Fitts' Law Model Builder intended for it to be used in human 
computer interaction research, such as the study being conducted. The software is available via anonymous FTP through the Internet at the following URL: ftp://snowhite.cis.uoguelph.ca

In this study, Generalized Fitts' Law Model Builder was used to capture data by configuring the available parameters accordingly. The available parameters include target shape (circle, square, rectangle or word in text), amplitude (distance from starting point to the target), target width (horizontal size), target height (vertical size), and approach angle (from the starting point to the target). The type of selection task (discrete drag or point or serial drag or point) is also configurable in addition to the number of repetitions of the trials for each task type, and how the user indicates the beginning or ending of the trial. The detailed procedures for test configuration and testing for this study are described in the Methods section of the thesis under "Data Collection Protocol". The collection of data includes movement times from the beginning to the end of each individual trial (as denoted by the beginning and ending task selected during configuration) and error count for each trial. The software also provides a summary of the data for each participant.

Computer system configuration. The software for the experiment required a personal computer system with minimum of $4 \mathrm{MB}$ of RAM and a $280^{\circ} \mathrm{F}$ graphics board with $1 \mathrm{MB}$ of RAM. In this study the background color of the screen was black, the starting box (where the participants cursor is set before the task begins) was purple, the cross-hair cursor was white and the targets were outlined in purple. 
Input devices. Cursor control and target selection were controlled by a mouse, a trackball and a graphics tablet using a digital pen. The mouse was a Logitech First Mouse ${ }^{\circledR}$ with two buttons. The mouse cursor is manipulated by the user moving their whole hand (initiating movement from the shoulder while holding the mouse in their hand) and selections are made by depressing the left button with the first finger (see Figure 1).

The trackball was a Logitech Cordless TrackMan Wheel®, which has a right thumb-operated ball and two selection buttons on the right side of the device. Cursor movement with the trackball is controlled by the user's thumb, while the hand rests on the device and the arm remains in a static posture (see Figure 2). The muscles involved in this fine motor skill of the thumb are the flexor pollicis longus, which is responsible for thumb flexion, or the movement of the thumb towards the palm of the hand, and the extensor pollicis longus, which is responsible for extension, or straightening, of the thumb.

The selection motion with the mouse and the trackball are similar in that they both require the user to depress a button with their index finger. The muscles involved in this motion are the flexor digitorum superficialis and the flexor digitorum profundus, which are responsible for finger flexion, or bending the fingers, and the extensor digitorum and the extensor endicis, which are responsible for finger extension, or straightening the fingers. With the mouse, the user must hold the device still while pressing the button, whereas with the trackball, as long as the user removes their thumb from the ball the device and the cursor remains still while the making a selection. 


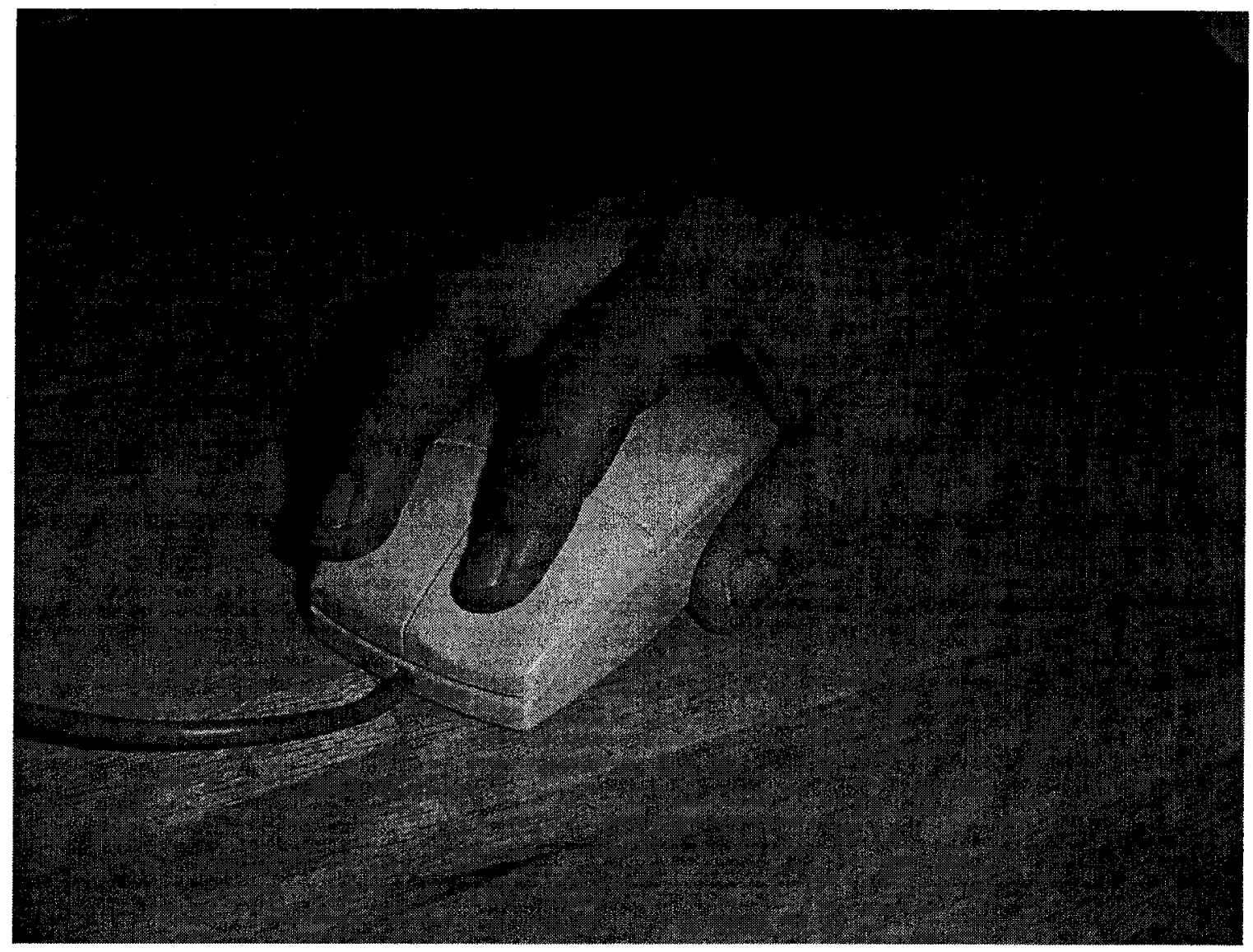

Figure 1. User manipulating the mouse. Cursor is moved by the whole hand moving while holding the mouse. Selections are made by depressing the left button with the first finger. 


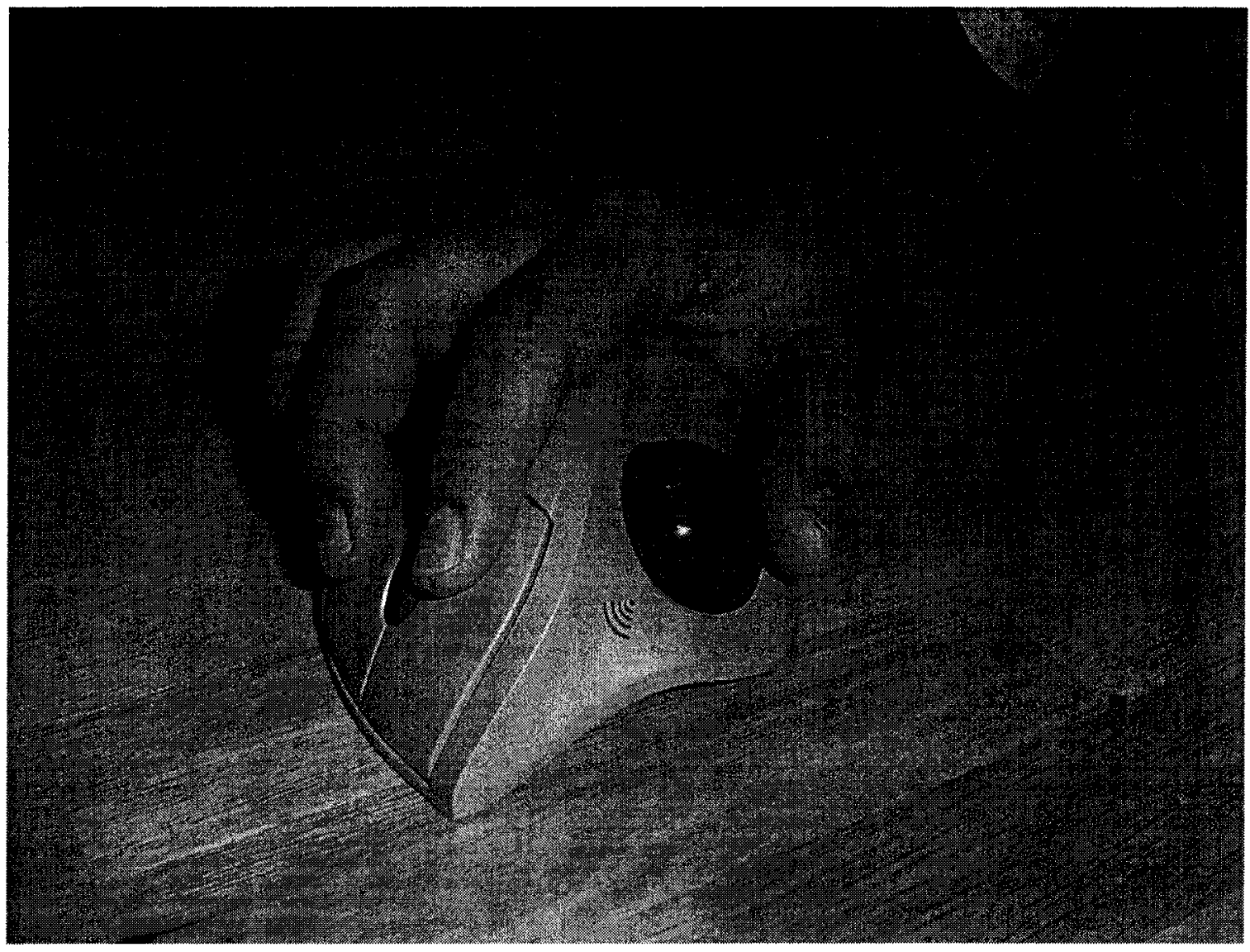

Figure 2. User manipulating the trackball. Cursor is moved by resting the hand on the device and moving the thumb on the ball. Selections are made by depressing the left button with the first finger. 
The graphics tablet was an Aiptek Hyper Pen ${ }^{\mathrm{TM}}$ 6000U. This set includes a 4.5 inches $\mathrm{x} 6$ inches tablet and a pen with selection button. The graphics tablet cursor is manipulated by the user holding the digital pen like they would an ink pen and moving its tip across the pad's surface. Selections are made by depressing the tip of the pen onto the pad while holding the position of the pen still (see Figure 3). A combination of all of the previously stated thumb and finger flexor and extensor muscles are needed for this motion as the pen is manipulated in a pinch grip between the thumb and index finger.

Dexterity measurement device. The Purdue Pegboard developed in 1948 by Joseph Tiffin, Ph.D., an Industrial Psychologist from Purdue University, was used to measure the manual dexterity of the participants. A series of four tests are conducted with this tool (right hand, left hand, both hands, and assembly) in which the user picks up (using predominantly their thumb and first finger with a pinch grip) small metal pins one at a time from a cup located at the top of the board and places the pins in holes situated in vertical rows. The user is instructed to manipulate as many pins as possible in a set time interval. Their score is the number of pins correctly placed. Individual performance is rated relative to normative data for specific populations. Normative data for people aged 60 years and older is available (Desrosiers et al., 1995) and were used in the presented study to rate the participants' level of manual dexterity as a percentile of the norm. Participants

The sample consisted of men and women age 65 years and older who are members of the City of Mountain View Senior Center in Mountain View, California or the Life Garden assisted living facility in Sunnyvale, California. The participants 


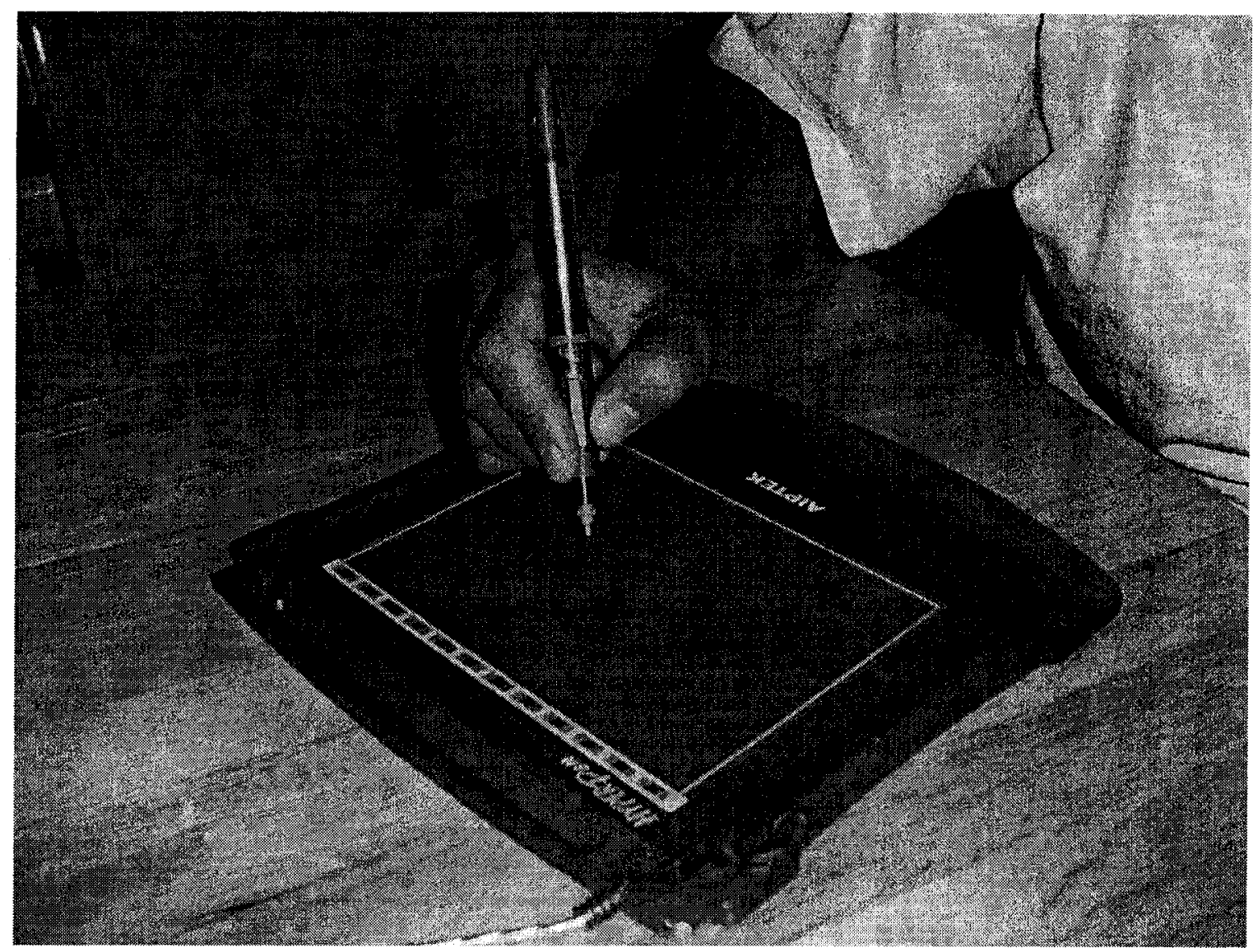

Figure 3. User manipulating the graphics tablet with digital pen. Cursor moves when the user moves the tip of the pen across the pad (like an ink pen on paper). Selections are made by the user depressing the tip of the pen into the pad. 
reported at least a total of 20 hours of computer experience with a Windows-based operating system. Because the sample was not a random sample of the American population of males and females of age 65 years and older, a threat to external validity exists in that the results may not be generalizable outside of these groups. In other words, the members of the Mountain View Senior Center and of Life Garden may exhibit characteristics that are different from those in the rest of the American population of older adults, to which the results of this study may be attributable.

\section{Data Collection Protocol}

Configuration of data collection software. All of the adjustable parameters were controlled by means of a configuration file. This file uses simple syntax and can be edited, created, or modified with a DOS text editor. Additionally, there is a set up screen through which all the parameters can be set. This set up screen was used to configure the software for the experiment.

The Generalized Fitts' Law Model Builder software was configured twice, once for the point-and-click task ("TaskType: discrete pointing") and once for the drag-anddrop task ("TaskType: discrete dragging"). These two tasks were used because together they are a good representation of actual tasks performed while using computers and the Internet. All parameters other than "TaskType" remained the same between the two tasks and were set as follows (see Figure 4 for an annotated screen shot of the Generalized Fitts' L.aw Model Builder software): “TaskBeginning: Mouse Click”, "'TaskEnding: Correct Mouse Click", "Target: Square", "ErrorBeep: Yes", "PracticeSession: Yes", "AmplitudeConditions: 40, 160", "WidthConditions: 8", "AngleConditions: 45, 135, 225, 


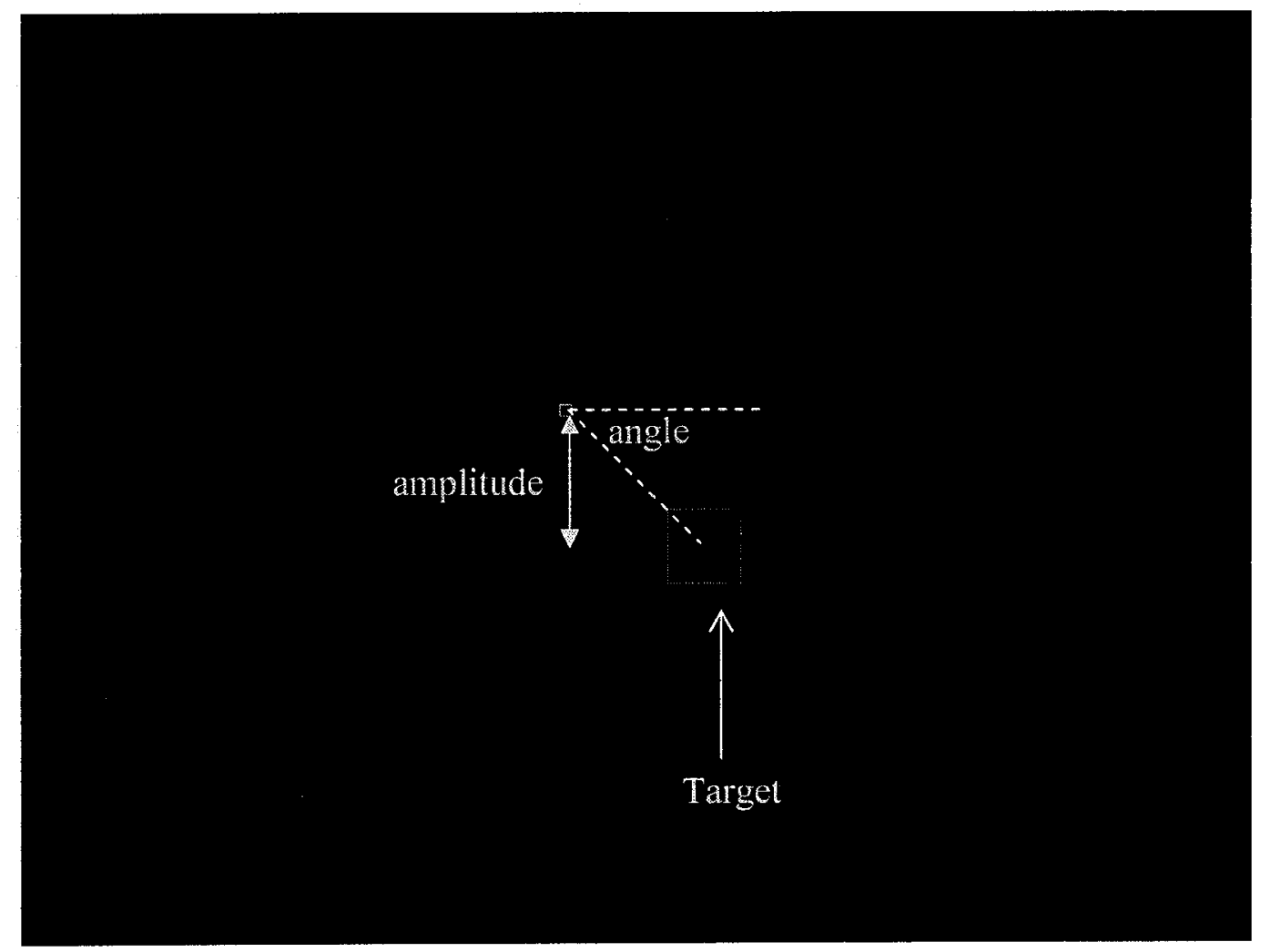

Figure 4. Annotated screen shot of Generalized Fitts' Law Model Builder software with terms used in configuration. 
315", "TrialsPerCondition: 2", "CDGainCondition: 1.0". The practical translation of this configuration is explained in the Experiment procedure section below.

Configuration of devices. Once the driver and software for each device were installed on the testing computer, the properties for that device were adjusted. The cursor speed was adjusted to a moderate to slow level and further adjustments were made so that the cursor speed of each device is comparable.

Experiment procedure. Approval from the Institutional Review Board was obtained from the Division of Graduate Studies and Research at San Jose State University (see Appendix A). Participants were tested individually in a space with only the experimenter present. Upon entering the room, the participant was greeted by the experimenter with a time appropriate greeting (i.e., "good morning" or "good afternoon"). They were then asked to sit in a chair situated in front of the computer, and read and sign an informed consent form (see Appendix B). Each participant was then interviewed to gather demographic data (age, gender, declared mousing hand and physical limitations) and familiarity with various computer devices (PC, mouse, trackball, and graphics tablet). The experimenter documented these data manually on a questionnaire (see Appendix C).

At this time, the experimenter administered the Purdue Pegboard test and recorded each participant's performance for the four tests (see Appendix C). Specific procedures for administration of the Purdue Pegboard test are included in the Test Administrator's Manual (see Appendix D). 
The participant then read a single page of written instructions before beginning the main portion of the experiment (see Appendix E) to become familiar with the testing procedure.

The testing procedure was as follows: For the first device and task type, the administrator demonstrated the task to familiarize the participant with the task, device, and the computer-testing environment, and answered any questions the participant had about the tasks (movement times and error for the demonstration session were recorded in a data file specifically created for demonstration purposes and were not used in the analysis). This demonstration session included several trials and was completed when the participant verbally expressed understanding of the concept.

Next, a practice session of trials was executed by the participant to overcome the learning curve (see Pilot Study section) for these tasks and to discover any problems they might have had with understanding the procedure (movement times and error for the practice session was recorded in a data file specifically created for participant practice on this task type with a given device and were not used in the analysis). Implementing this practice session attempted to reduce the threat to internal validity that might have caused by practice effects during the course of the tests. This practice session was repeatable if the participant expressed interest in further practice. When ready, the participant verbally indicated that she had performed a sufficient amount of practice and that she felt comfortable with the task at hand.

Finally, a new data file was opened for the main test for the first task type and the first input device. Only the data collected during the main test was used in the analysis. 
The participant was instructed to perform each trial as quickly and as accurately as possible, and a message appeared on the screen when the set of trials was completed. This patterned procedure of demonstration, practice, and a main test was repeated for each task type (drag/drop and point/click) and each device (mouse, trackball, and graphics tablet). The order in which the task type and the device were presented was counterbalanced across the study (see Table 1 for balanced order). The orders of device and task presentation were counterbalanced in an attempt to maintain the attention of and decrease the fatigue and boredom of the participants, however, order effects were not statistically analyzed. A rest period of two minutes between each set of trials provided the participants with an opportunity to rest their arms and hands, and ask any questions. The total length of the study did not exceed one hour for each participant. During the main test, each participant completed a set of trials for each task type for each device, six total sets. Each set tested one task type using one device, and consisted of 16 individual trials, representing the combinations of each angle of approach and amplitude twice. A total of 96 individual trials were presented for each participant throughout the entire experiment. This high number of trials was necessary to ensure that all possible combinations of angles and amplitudes were covered by the experiment.

As configured by the software, the starting box and the target were simultaneously displayed with the target positioned at its angle and amplitude for the point-and-click task. When ready, the participant depressed the input button (up/down) and the starting box changed into a cross-hair cursor. The participant moved the cursor to the target as rapidly as possible, and depressed the input button to complete the selection 
Table 1

Order of device and task type presentation

\begin{tabular}{|c|c|c|c|c|c|c|}
\hline \multirow[b]{2}{*}{ ID Number } & \multirow[b]{2}{*}{ Date Tested } & \multicolumn{3}{|c|}{ Order of device } & \multicolumn{2}{|c|}{ Order of task type } \\
\hline & & Mouse & Trackball & Tablet & $\mathrm{P} / \mathrm{C}$ & $\mathrm{D} / \mathrm{D}$ \\
\hline 01 & $06 / 13 / 03$ & 1 & 2 & 3 & 1 & 2 \\
\hline 02 & $06 / 13 / 03$ & 2 & 3 & 1 & 2 & 1 \\
\hline 03 & $08 / 04 / 03$ & 3 & 1 & 2 & 1 & 2 \\
\hline 04 & $08 / 12 / 03$ & 1 & 2 & 3 & 2 & 1 \\
\hline 05 & $08 / 12 / 03$ & 2 & 3 & 1 & 1 & 2 \\
\hline 06 & $08 / 15 / 03$ & 3 & 1 & 2 & 2 & 1 \\
\hline 07 & $08 / 15 / 03$ & 1 & 2 & 3 & 1 & 2 \\
\hline 08 & $08 / 15 / 03$ & 2 & 3 & 1 & 2 & 1 \\
\hline 09 & $08 / 15 / 03$ & 1 & 2 & 3 & 2 & 1 \\
\hline 10 & $08 / 15 / 03$ & 3 & 1 & 2 & 2 & 1 \\
\hline 13 & $08 / 16 / 03$ & 1 & 2 & 3 & 1 & 2 \\
\hline 14 & $08 / 16 / 03$ & 2 & 3 & 1 & 2 & 1 \\
\hline 15 & $08 / 16 / 03$ & 3 & 1 & 2 & 1 & 2 \\
\hline 16 & $08 / 20 / 03$ & 1 & 2 & 3 & 2 & 1 \\
\hline 17 & $08 / 20 / 03$ & 2 & 3 & 1 & 1 & 2 \\
\hline 18 & $08 / 20 / 03$ & 3 & 1 & 2 & 2 & 1 \\
\hline 19 & $08 / 21 / 03$ & 1 & 2 & 3 & 1 & 2 \\
\hline 20 & $08 / 21 / 03$ & 2 & 3 & 1 & 2 & 1 \\
\hline 21 & $08 / 21 / 03$ & 3 & 1 & 2 & 1 & 2 \\
\hline 22 & $08 / 25 / 03$ & 1 & 2 & 3 & 2 & 1 \\
\hline
\end{tabular}


(down). If the cross hair was within the target, the trial was complete, and the participant proceeded to the next trial. If the cursor was not in the target, the computer beeped and that trial continued until the participant successfully selected the target (see Figure 5 for screen-shot illustration of main test). The drag-and-drop task required the participant to hold the input button down and to 'drag' the cursor to the target. The participant released the input button (up), 'dropping' the cursor within the target to complete the task. The GFLMB software recorded movement time in milliseconds and number of errors for each combination of angle of approach, amplitude, and task type. When the participant incorrectly ended the task by clicking the button but was not situated in the target, the participant heard a beep and movement time continued to accrue until she correctly ended the task. For data analyses, the movement times were compressed into one average score for each participant for each task type and each device (six average movement times for each participant).

Pilot Study

A pilot study was conducted with two volunteers from the specified population. Observation by the experimenter, and verbal communication between the administrator and the participants resulted in some adjustments to the data collection protocol.

Observed frustration on the part of the volunteers and subsequent conversation with them regarding the speed of the cursor led to a decrease in the cursor speed for the trackball (making the cursor move slower on the screen).

Another goal of the pilot study was to determine the necessary length of the practice session. The practice session provides the participant exposure to the device so 
Start click turns small square into crosshair and time begins

Correct end click in target ends trial

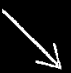

Incorrect end click outside of target counts as an error and trial continues until correct end click in target

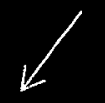

Figure 5. Annotated screen shot illustration of main test. 
that when they perform the main test, they are performing to the best of their abilities and not still in a state of learning. A set of sixteen trials was used as a practice session during the pilot study. Both of the pilot study participants had no previous experience with the graphics tablet, and therefore, the proposed practice session was examined using this device.

The experimenter observed the participants learning to use the graphics tablet and interviewed them to understand their level of comfort after the proposed practice session. Based on the observed decreased change in movement time and error, it appeared that the participant had overcome the learning curve at or before the sixteenth trial. Verbal conversation with the participant confirmed this suggestion. The practice session was determined to include one set of 16 trials for each device (however, more practice was allowed during the experiment if deemed necessary by the experimenter or if requested by the participant).

Research Design

The research design (Table 2) for this study was a repeated measures design (single factor within subjects). There were two independent variables, computer input device and task type. The input device independent variable had three levels: mouse, trackball, and graphics tablet, and the task type independent variable had two levels: drag/drop and point/click. Each participant was tested with both task types on all three devices.

The dependent variables were movement time and error. Movement time did not include reaction time in this study, because the participant initiated the timed trial. 
Table 2

Repeated measures research design recorded movement time (MT) and error (E) for each combination of the two independent variables (input device and task type).

\begin{tabular}{ccccccc}
\hline & \multicolumn{5}{c}{ Input Device } \\
\cline { 2 - 7 } Task type & \multicolumn{3}{c}{ Mouse } & \multicolumn{2}{c}{ Trackball } & Graphics Tablet \\
\hline Point/click & MT & E & MT & E & MT & E \\
Drag/drop & MT & E & MT & E & MT & E \\
\hline
\end{tabular}


Movement time was recorded in milliseconds for each trial. The movement time was the time from when the user initiated and completed movement, as configured with the software. The averages of all of the movement times for each participant, for each device, for each task type were calculated and used as the individual's scores for analysis (each participant produced six average scores, one for each device, for each task type). The error counts for each set of trials were added together to form an overall error for each participant, for each device, for each task type (six total error values for each participant).

\section{Results}

\section{Descriptive Statistics}

Descriptive statistics were computed using SPSS 11.5 for the demographic variables (gender, age, computer, mouse, trackball and graphics tablet experience, and manual dexterity) in order to check the data and determine any trends. The minimums, maximums, means and standard deviations of the demographic variables are presented in Table 3. There were twice as many female $(n=14)$ participants than male $(n=7)$. The sample in this study was limited to people age 65 years and older. The youngest participant was 65 , the oldest was 93 , and the mean age of the sample $(n=21)$ was 76 years old.

The methodology of the study required that the participants have at least a total of twenty hours of computer experience, however, the average for the sample was 7.7 years. The minimum length of experience of the sample was one year and the maximum was 25 years. There were no experience requirements for the mouse, trackball or the graphics 
Table 3

Descriptive statistics of demographic variables $(N=21)$.

\begin{tabular}{lccccc}
\hline & Count & Mean & Min. & Max. & Std. Dev. \\
\hline Gender & & & & & \\
$\quad$ Male & 7 & & & & \\
$\quad$ Female & 14 & & & & \\
Age (years) & & 76.0 & 65.0 & 93.0 & 6.9 \\
Computer experience (years) & & 7.7 & 1.0 & 25.0 & 6.7 \\
Mouse experience (years) & 7.1 & 1.0 & 20.0 & 5.6 \\
Trackball experience (years) & 0.1 & 0.0 & 1.0 & 0.2 \\
Graphics tablet experience (years) & 0.0 & 0.0 & 0.0 & 0.0 \\
Manual dexterity (percentile of & & & & & \\
normative data for population) & 43.0 & 85.0 & 2.0 & 19.1 \\
\hline
\end{tabular}


tablet. All of the participants were familiar with using the mouse and the sample had a mean length of experience of 7.1 years. Only one participant had previous experience using a trackball, but several indicated that they had seen one before. The reported length of trackball experience by the one participant was one year. None of the 21 participants had ever used a graphics tablet with a digital pen for computer input purposes.

Immediately following the collection of demographic data, the participants' manual dexterity was measured using the Purdue Pegboard. The five subsets of data (i.e., right hand, left hand, both hands, sum of right/left/both, and assembly) were compared with normative data for the population (Desrosiers et al., 1995), and a percentile ranking was generated for each data subset for each participant. These percentile rankings were then combined to form an average percentile ranking of manual dexterity for each participant. The mean percentile ranking of manual dexterity was 43.0 , which indicates that as a group, the sample was slightly less dexterous than average (where average is a 50.0 percentile ranking) for their population. The range of dexterity level for the sample was wide. The minimum was a percentile ranking of 2.0 and the maximum was 85.0.

Although all five subsets of percentile manual dexterity data (i.e., right hand, left hand, both hands, sum of right/left/both, and assembly) were analyzed as demographics for the sample, only the raw data from the right hand portion of the Purdue Pegboard test were further used in the analyses since the main test involved the manipulation of input devices with the right hand only (see Table 4 for dexterity scores by participant). 
Table 4

Purdue Pegboard raw scores and percentiles of normative manual dexterity data by participant

\begin{tabular}{|c|c|c|c|c|c|c|c|c|c|c|c|c|}
\hline \multirow[b]{2}{*}{ ID } & \multirow[b]{2}{*}{ Gender } & \multirow[b]{2}{*}{ Age } & Right land & \multicolumn{2}{|c|}{ Left Hand } & \multicolumn{2}{|c|}{ Both Hand } & \multicolumn{2}{|c|}{ Sum of $R+L$} & \multicolumn{2}{|c|}{ Assembly } & \multirow{2}{*}{$\begin{array}{c}\text { Overall } \\
\%\end{array}$} \\
\hline & & & Raw $\%$ & Raw & $\%$ & Raw & $\%$ & Raw & $\%$ & Raw & $\%$ & \\
\hline 01 & f & N/A & $11=25$ & 14 & 80 & 11 & 73 & 87 & 60 & 23 & 46 & $19 \%$ \\
\hline 02 & $\mathrm{~m}$ & 70 & 13 & 15 & 100 & 12 & 99 & 114 & 99 & 23 & 50 & $27 \%$ \\
\hline 03 & $\mathrm{~m}$ & 83 & 20 & 11 & 70 & 8 & 58 & 69 & 50 & 17 & 50 & $15 \%$ \\
\hline 04 & f & 75 & 14 & 10 & 25 & 10 & 52 & 62 & 50 & 24 & 45 & $17 \%$ \\
\hline 05 & $\mathrm{f}$ & 81 & 47. & 10 & 45 & 10 & 75 & 85 & 50 & 19 & 40 & $16 \%$ \\
\hline 06 & f & 67 & 13 & 11 & 0 & 10 & 40 & 51 & 8 & 26 & 30 & $9 \%$ \\
\hline 07 & $\mathrm{f}$ & 64 & 13 & 14 & 52 & 14 & 100 & 114 & 65 & 35 & 72 & $23 \%$ \\
\hline 08 & $\mathrm{~m}$ & 77 & 12 & 14 & 90 & 9 & 60 & 74 & 75 & 22 & 45 & $21 \%$ \\
\hline 09 & $\mathrm{~m}$ & 84 & 7 & 9 & 40 & 6 & 25 & 34 & 25 & 12 & 0 & $9 \%$ \\
\hline 10 & $\mathrm{~m}$ & 73 & 48 & 12 & 63 & 9 & 58 & 70 & 60 & 22 & 45 & $18 \%$ \\
\hline 13 & $\mathrm{f}$ & 77 & 12 & 12 & 52 & 9 & 47 & 59 & 45 & 17 & 17 & $14 \%$ \\
\hline 14 & $\mathrm{~m}$ & 78 & 14. & 11 & 53 & 9 & 60 & 71 & 72 & 20 & 38 & $20 \%$ \\
\hline 15 & $\mathrm{~m}$ & 67 & 12 & 11 & 22 & 10 & 47 & 58 & 37 & 21 & 18 & $14 \%$ \\
\hline 16 & $\mathrm{f}$ & 80 & 9.17 & 11 & 52 & 5 & 7 & 18 & 25 & 12 & 5 & $8 \%$ \\
\hline 17 & $\mathrm{f}$ & 78 & 11. & 12 & 52 & 7 & 10 & 22 & 25 & 21 & 32 & $11 \%$ \\
\hline 18 & $\mathrm{f}$ & 93 & 11 & 10 & 43 & 8 & 48 & 58 & 46 & 18 & 38 & $14 \%$ \\
\hline 19 & f & 75 & 10 & 13 & 70 & 10 & 53 & 66 & 45 & 24 & 45 & $16 \%$ \\
\hline 20 & f & 81 & $11=45$ & 7 & 8 & 9 & 60 & 67 & 38 & 15 & 20 & $12 \%$ \\
\hline 21 & f & 78 & $13: 55$ & 11 & 40 & 10 & 55 & 66 & 50 & 23 & 40 & $17 \%$ \\
\hline 22 & f & 72 & $11=25$ & 11 & 40 & 8 & 25 & 36 & 25 & 20 & 30 & $11 \%$ \\
\hline 23 & $\mathrm{f}$ & 66 & $10: 0$ & 10 & 0 & 7 & 0 & 10 & 0 & 22 & 12 & $6 \%$ \\
\hline
\end{tabular}




\section{Pearson Correlations}

A correlation analysis was conducted using SPSS 11.5 to examine the relationships among right hand manual dexterity (raw score on right hand only task of Purdue Pegboard Test), computer and mouse experience (Note: due to the sample's lack of previous experience with the trackball and the graphics tablet, only the recorded values for mouse and computer experience were used in the analysis), and movement time and error. The results of this analysis answer the final research question posed in this study which stated: Is there a relationship between manual dexterity, length of previous experience, movement time, and error in computer tasks performed by older adults?

Results of this analysis indicate a negative relationship between right hand dexterity and error when using the trackball on point/click tasks $\left(r=-.461, p<.05, r^{2}=\right.$ .21 ), This finding indicates that as the user's level of dexterity increases, the amount of errors on point/click tasks with a trackball decreases. The large effect size suggests that the user's right hand dexterity score can explain $21 \%$ of the variability in the error.

These results also show a negative relationship between right hand dexterity and movement time with the graphics tablet on point/click tasks $\left(r=-.473, p<.05, r^{2}=.22\right)$, This finding indicates that as the user's level of dexterity increases, the movement time on point/click tasks with a graphics tablet decreases. The effect size suggests that the user's right hand dexterity score can explain $22 \%$ of the variability in movement time.

Although these two significant relationships were found in the correlation analysis, no trend was identified. Therefore in partial answer to the final research 
question, there exists no relationship between dexterity, movement time and error for the sample of older adults.

The relationship between previous experience and movement time and error was also evaluated in this correlation analysis. Because only one participant had previous experience with a trackball and none had ever used a graphic tablet before, only computer and mouse experience were included in this correlation analysis. Of these relationships, statistically significant correlations were found between computer experience $(r=-.446$, $\mathrm{p}<.05, \mathrm{r}^{2}=.20$ ) and error when using the trackball for drag/drop tasks, and mouse experience $\left(r=-.450, p<.05, r^{2}=.20\right)$ and error when using the trackball for drag/drop tasks. These findings indicate that users with longer computer or mouse experience perform significantly fewer errors with the trackball on drag/drop tasks. The effect size suggests that the length of the user's previous mouse or computer experience can explain $20 \%$ of the variability in their error when using the trackball for drag/drop tasks.

Although these two relationships were found in the correlation analysis, no trend was identified. Therefore in partial answer to last research question, there exists no relationship between length of previous mouse or computer experience, movement time and error for the sample of older adults.

Other statistically significant correlations were determined in this analysis and can be found in Table 5. With the exception of the movement time with the graphics tablet for point/click tasks, all of the movement time measurements were positively and significantly correlated with the other movement time measurements. These results indicate that if users perform tasks quickly with one device, they will tend to perform the 

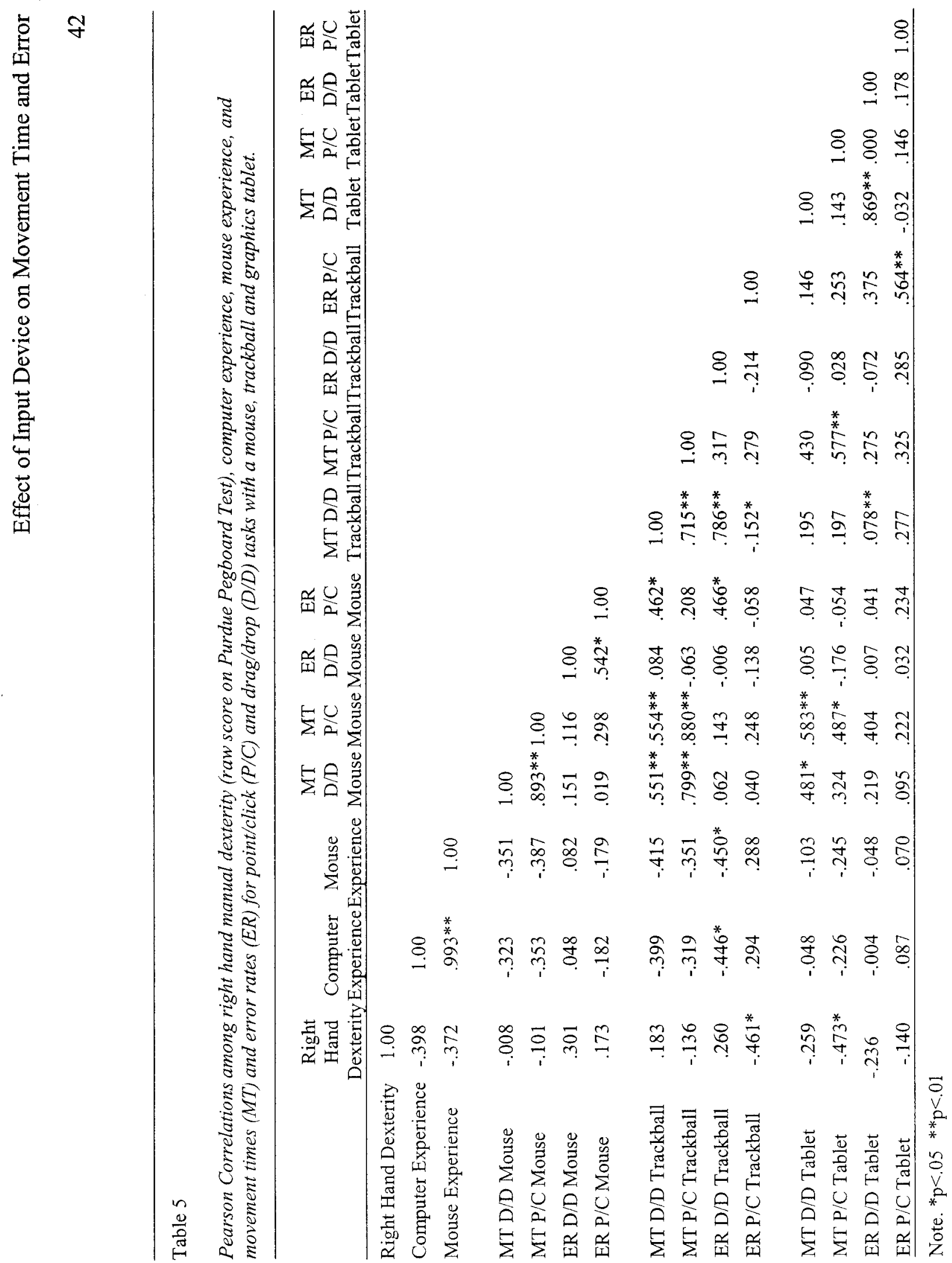
same tasks quickly with the other devices as well. In summary, the results of this study indicate no clear trends between right hand manual dexterity, movement time and error, or a relationship between length of computer or mouse experience and movement time and error.

Repeated Measures ANOVA

Results of the correlation analysis indicated no significant relationship trends between dexterity, movement time and error; therefore it was unfeasible to use dexterity as a covariate in an analysis of covariance (ANCOVA) to analyze the differences in mean movement times and errors. Instead, two $3 \times 2$ repeated measures (within-subjects) analyses of variance (ANOVA) were conducted using SPSS 11.5 with input device (three levels: mouse, trackball, graphics tablet) and task type (two levels: point/click, drag/drop) as independent variables and movement time and error as dependent variables (two total main analyses, evaluated at $\alpha=.05$ ). These analyses were conducted to answer the first three research questions as to the effects of input device and task type on movement time and error of computer users age 65 and older.

The first ANOVA (see Table 6 and Figure 6) examined differences in mean movement times. The overall analysis showed a main effect for the type of device on the movement time, $F(2,40)=60.92, p<.01, R^{2}=.79$. No main effect was found for task type in terms of movement time, nor was there a significant interaction effect found between device and task type.

Because a main effect was found for device type, further analyses (evaluated at $\alpha$ $=.017$ ) were conducted to examine with which device the users performed best in terms 
Table 6

ANOVA Summary Table for Movement Time $(N=21)$.

\begin{tabular}{lrrrc}
\hline Source & SS & df & MS & F \\
\hline Device & $39,639,283.46$ & 2 & $19,819,641.73$ & $60.92^{* *}$ \\
Task type & $11,766.27$ & 1 & $11,766.27$ & 0.04 \\
Device*Task & $582,579.33$ & 2 & $291,289.67$ & 1.14 \\
Error & $10,224,324.04$ & 40 & $255,608.10$ & \\
Total & $50,457,953.10$ & 45 & $20,378,305.77$ & \\
\hline
\end{tabular}

Note. ${ }^{*} \mathrm{p}<.05{ }^{* *} \mathrm{p}<.01$ 


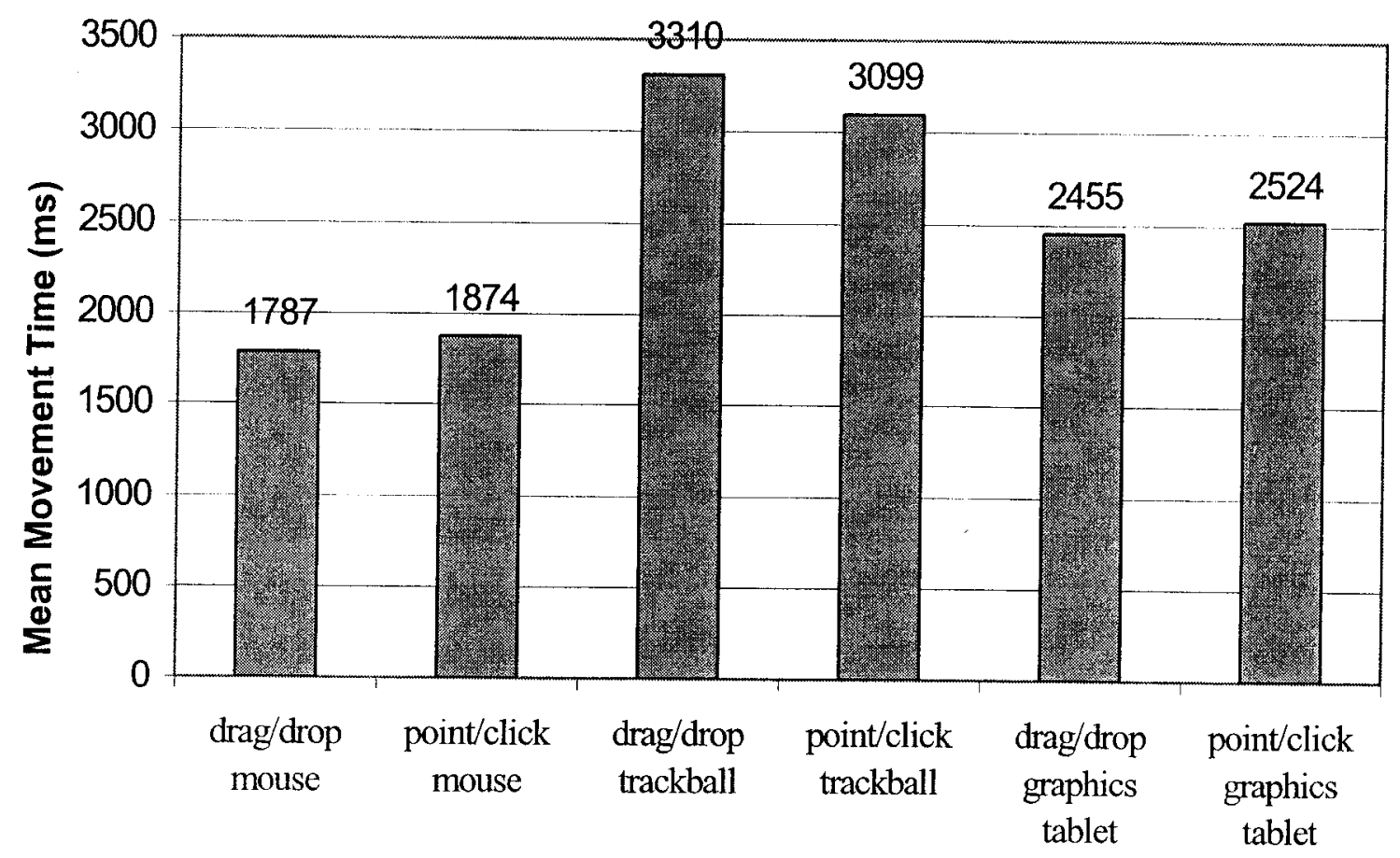

Figure 6. Mean movement times in milliseconds for each task type and device type combination. 
of movement time. Results of within-subjects contrasts of mean movement time showed that movement time with the mouse $(\mathrm{M}=1830.84 \mathrm{~ms})$ was faster than with the graphics tablet $(\mathrm{M}=2488.4 \mathrm{~ms}), \mathrm{F}(1,21)=175.9, \mathrm{p}<.01$. The average movement time with the graphics tablet was faster than with the trackball $(M=3204.35 \mathrm{~ms}), F(1,21)=22.12$, $\mathrm{p}<.01$. To summarize the findings of this analysis, participants produced fastest movement times with mouse, second fastest with the graphics tablet, and the slowest movement times with the trackball.

The second ANOVA (see Table 7 and Figure 7) examined differences in error as a function of input device and task type. The overall analysis showed a main effect for the type of device on error, $\mathrm{F}(2,40)=34.22, \mathrm{p}<.01, \mathrm{R}^{2}=.48$. There was also a main effect for task type on error, $\mathrm{F}(2,40)=5.03, \mathrm{p}<.05, \mathrm{R}^{2}=.04 . \quad$ Finally, an interaction effect between device and task type on error was obtained, $F(2,40)=5.12, p<.05, R^{2}=$ .10 .

In order to determine the source and nature of the significant interaction effect, simple effect analyses were conducted, examining the effect of device type on error for the drag/drop and the point/click task types. The simple effect for device type for the drag/drop task type was significant, $\mathrm{F}(2,40)=9.06, \mathrm{p}<.05, \mathrm{R}^{2}=.31$. Further simple comparisons (evaluated at $\alpha=.017$ ) revealed that with $\mathrm{drag} / \mathrm{drop}$ tasks, participants made fewer errors with the mouse $(M=.67)$ than with the trackball $(M=3.81)$ and the graphics tablet $(M=4.19)$, which did not differ from each other.

The simple effect for device type for the point/click task type was also significant, $\mathrm{F}(2,40)=42.08, \mathrm{p}<.01, \mathrm{R}^{2}=.68$. Further simple comparisons (evaluated at $\alpha=.017$ ) 
Table 7

ANOVA Summary Table for Error $(N=21)$.

\begin{tabular}{lrrrc}
\hline Source & SS & df & MS & F \\
\hline Device & 328.62 & 2 & 164.31 & $34.22^{* *}$ \\
Task type & 24.01 & 1 & 24.01 & $5.03^{*}$ \\
Device*Task & 68.87 & 2 & 34.44 & $5.12^{* *}$ \\
Error & 269.13 & 40 & 6.73 & \\
Total & 690.63 & 45 & 229.49 & \\
\hline
\end{tabular}

Note. ${ }^{*} p<.05 * * p<.01$ 


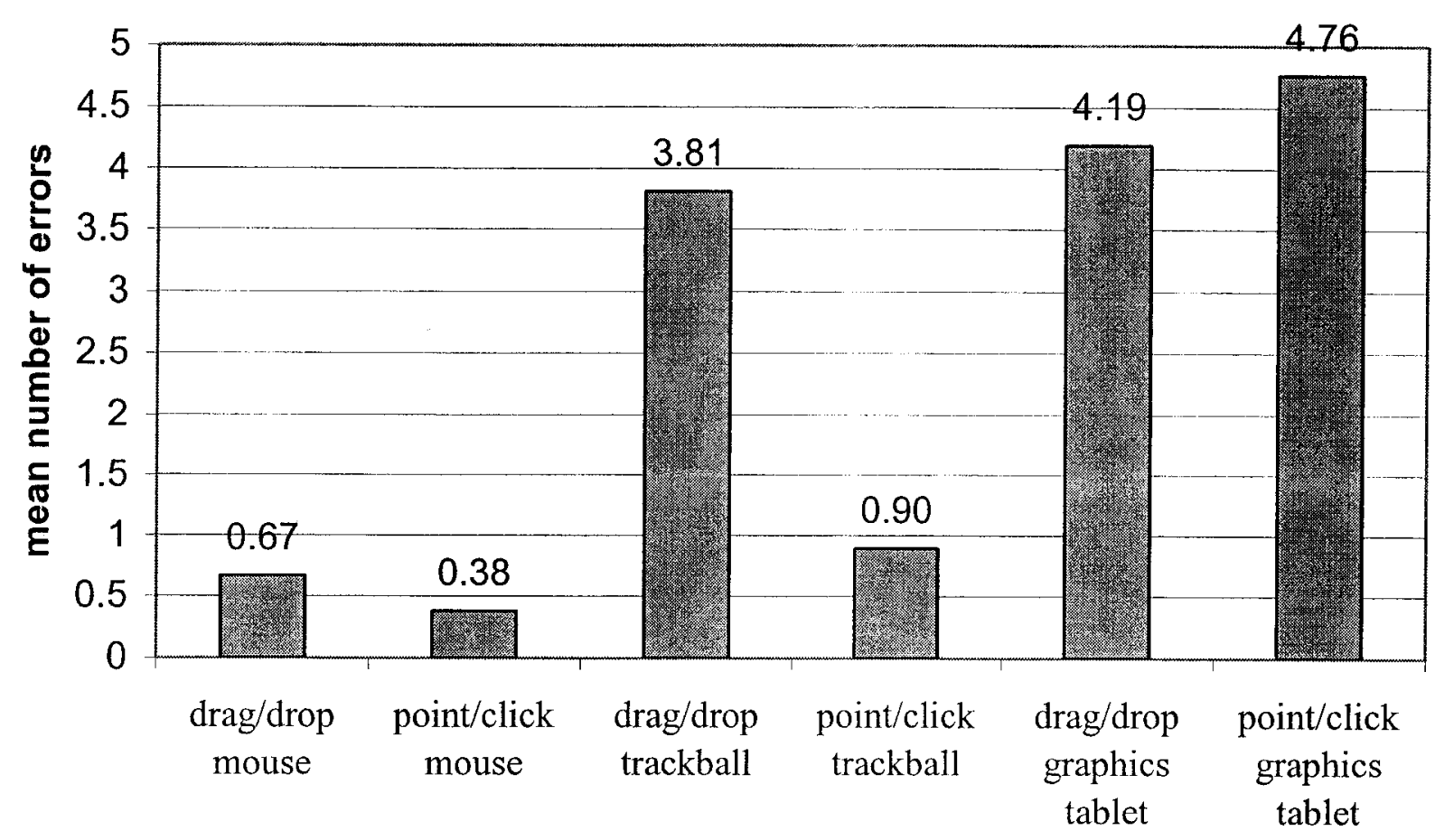

Figure 7. Mean error for each task type and device type combination. 
revealed that with point/click tasks, participants made fewer errors with the mouse $(M=$ $.38)$ than with the trackball $(\mathrm{M}=.90)$ and fewer errors with the trackball than with the graphics tablet $(\mathrm{M}=4.76)$.

To summarize the findings of this analysis, participants produced fewer errors on drag/drop tasks with the mouse than with the trackball and the graphics tablet. With the point/click task, participants produced the lowest number of errors with mouse, followed by the trackball, and they produced the highest number of errors when using the graphics tablet.

\section{Discussion}

The purpose of this study was to determine the effects of device and task type on movement time and error among computer users aged 65 years and older. In addition, the relationship between manual dexterity, previous experience, movement time and error was investigated. Movement time and error were measured on three different computer input devices (mouse, trackball, and graphics tablet) on two different task types (dragand-drop and point-and-click).

The manipulation of each device includes two types of motion: moving the cursor and making selections. As described in the Input Device portion of the Methods section of this paper, each device differs in terms of motor control of these motions. Cursor movement with the mouse and the graphics tablet is controlled by the user holding the device in their hand while movement is initiated from the shoulder region. In contrast, cursor movement with the trackball is controlled by the user's thumb, while the hand 
rests on the device and the arm remains in a static posture. Movement time can represent cursor control as it measures the ability of the user to reach the target in a timely manner.

The selection motion with the mouse and the trackball are similar in that they both require the user to depress a button with their index finger. With the mouse, the user must hold the device still while pressing the button, whereas with the trackball, as long as the user removes their thumb from the ball, the device and the cursor remains still while making a selection. The selection motion with the graphics tablet is different and requires the user to depress the tip of the pen into the pad while holding the position of the pen still. Error rate can represent the efficiency of the user to perform this selection motion. If the user incorrectly performs the selection motion, an error is recorded.

Overall, the participants performed best with the mouse. They produced the fastest movement times and fewest errors with the mouse, regardless of task type. These findings are consistant with those of Baber (1997). The previous study, however, included participants from all age groups, not from the same population of older adults as the present study. Other previous research reviewed in this paper (Hancock, 1996; Harvey \& Peper, 1997) indicated that the trackball was superior to the mouse in terms of performance, subjective workload, and decreased muscle tension of users from all age groups.

The contradiction of the current results to these previous findings may be attributed to the specific population of older adults sampled in this study. Although, Chaparro et al. (1999) reported that older adults in particular exhibited faster movement times with the mouse and indicated personal preference for the trackball over the mouse. 
The methodology of the study (i.e., the population, the independent, and the dependent variables) by Chaparro et al. is the closest comparison to that of the present study, however the results do not agree.

Observations made by the experimenter during the testing procedure indicated that the participants in the present study were frustrated while using the trackball. They felt physically uncomfortable in that they had trouble holding the button down while moving the trackball with their thumb during the drag/drop tasks. This difficulty was also psychologically challenging in that they tended to lose confidence when they made errors. These observations suggest that judging the effectiveness of a computer input device only by movement time and error may not be sufficient. Future research could include measures of performance such as movement time and error, but could also include a psychological aspect in the form of participants' feelings or perception about the devices.

The participants reported the longest prior experience with the mouse, which possibly had some effect on the results, although the correlation between mouse experience and mouse performance (movement time and error) was not statistically significant. Future research could test participants with similar experience levels on each device, to more accurately compare performance. The practice session given at the start of each set of trials was intended to overcome this difference in experience by allowing the participant to learn the manipulation techniques of the device before performing the actual tests. The assumption was that after the practice session, the participant would generate performance data instead of learning data. An improved replication of this study 
could include only participants with the same amount experience using the three input devices, which would most likely entail finding participants who had not previously used a computer.

Second to the mouse in terms of movement time performance was the graphics tablet, followed by the trackball. This result may be explained by the similar motor control of the mouse and the graphics tablet. As mentioned previously, the cursor movement motion of the mouse and the graphics tablet is initiated from the shoulder region. The trackball requires movement initiated from the smaller muscles of the hand and forearm, and consequently this device was found to produce the slowest movement times. These results indicate that computer users age 65 and older have better control of computer input devices that use larger muscle groups. This may be related to a decrease in fine motor control associated with aging (Desrosiers et al., 1999; Galganski, Fuglevand, \&Maenoka, 1993; Houx \& Jolles, 1993; Smith et al., 1999; Vidal, Tuelings, \& Stelmach, 1998), or it may be attributed to a difference in motor control that is not related to aging at all. In other words, regardless of the age of the user, the motor control provided by the larger muscles in the shoulder may naturally be greater than that provided by the small muscles in the forearm and hand. Further research examining performance differences across all age groups would be appropriate to see if these trends hold true.

The answer to the final research question is applicable in the context of these ideas. In the present study, it was found that dexterity is not related to movement time or error. The non-significant findings may be due to the small sample size used in this 
study. However, this finding may also indicate the motor control measured specifically by the Purdue Pegboard is not related to computer task performance. Future research could implement different measures of manual dexterity that are more specifically representative of the fine motor skills used in manipulating a mouse, trackball, and graphics tablet.

In terms of error count, the trackball was second to the mouse, followed by the graphics tablet with which the participants performed the greatest amount of errors. The high number of errors with the graphics tablet may be due to the motor control needed to correctly select the target, but may also be attributed to the functionality of the hardware. In order to correctly select the target with the digital pen, the user must hold the pen still while depressing the small tip of the pen into the pad. This requires a good deal of fine motor control as the pen is held with a pinch grip (like an ink pen, between the thumb and index finger). The sensitivity of the pad was set at the least sensitive option (by means of the configuration of the graphics tablet software), however observations of the participants using this device during the experiment revealed instances of errors that were attributed to pad sensitivity issues and not actually user error. In other words, it was occasionally observed that a participant would technically make an error (i.e. hear a beep and have an error recorded) when they did not intentionally depress the tip of the pen into the pad. In the future this could be remedied by replacing the Aiptek graphics tablet with a higher-end device (such as the Wacom) that may have increased adjustability of tablet sensitivity. 
The error count for the point/click tasks with the trackball was only slightly higher than that of the mouse as compared to the differences between the error counts with the mouse and the graphics tablet. This finding makes sense given the similar selection motion used with both the trackball and the mouse. As previously mentioned, the mouse and the trackball both require the user to depress the left button with their index finger, while holding the cursor over the target. In terms of motor control this motion should be simpler with the trackball because the user does not need to physically hold their hand and arm still while making the selection, as they do with the mouse. The slightly lower error count for the mouse may be associated with the familiarity of the users to this device, as discussed earlier in this section.

To answer the final research question, the length of experience of the users with computers or any of the input devices was not related to their performance, with the exception of the amount of errors made when using the trackball for drag/drop tasks. This performance measure was negatively related to both computer and mouse experience, indicating that users with more experience make fewer errors. This finding, although statistically significant, may be attributed to chance since there is no found trend across other performance measures.

This paper presented results that could influence the type of computer input device that older users choose to utilize. The length of experience of each participant actually using the three devices was recorded in the beginning of the experiment. Only one of the participants had ever used a trackball but many had seen one before. None of the participants had ever used a graphics tablet and very few had ever seen one. This 
indicates that the trackball has a greater presence than the graphics tablet in the market. The comments made by the participants during and after the experiments indicate an interest in using the graphics tablet over the trackball for their personal computer use. In fact, most participants expressed frustration when using the trackball. The combination of the results of this study and the observations of the experimenter indicate that computer users age 65 and older may benefit from using a graphics tablet as an alternative to the mouse.

The findings of this study may also be of interest to computer peripheral device manufacturers or distributors. The mouse is currently the most common input device used and these results confirm the appropriateness of this. As an alternative, however, the graphics tablet could be marketed as an effective input device towards people age 65 and older, instead of primarily to users of graphic design or photo finishing software packages. 


\section{References}

Baber, C. (1997). The role of planning in pointing device use. International Journal of Cognitive Ergonomics, 1, 63-78.

Card, S.K., English, W.K., \& Burr, B.J. (1978). Evaluation of a mouse, ratecontrolled isometric joystick, step keys, and text keys for text selection on a CRT. Ergonomics, 21, 601-613.

Card, S.K., Moran, T.P., \& Newell, A. (1983). The psychology of human-computer interaction. Hillsdale, NJ: Lawrence Erlbaum Associates.

Chaparro, A., Bohan, M., Fernandez, J., Choi, S.D., \& Kattel, B. (1999). The impact of age on computer input device use: Psychophysical and physiological measures. Industrial Ergonomics, 24, 503-513.

Contreras-Vidal, J.L., Teuliings, H.L., \& Stelmach, G.E. (1998). Elderly subjects are impaired in spatial coordination in fine motor control. Acta Psychologica, 100, 25-35.

Cosro, J.F. (1981). Aging sensory systems and perception. New York: Praeger Publishers.

Czaja, S.J., \& Sharit, J. (1998). Age differences in attitudes towards computers. Journal of Gerontology, 53B, P329-P340.

Desrosiers, J., Herbert, R., Bravo, G., \& Dutil, E. (1995). The Purdue Pegboard Test: normative data for people aged 60 and over. Disability and Rehabilitation, 17, 217-224.

Desrosiers, J., Herbert, R., Bravo, G., \& Rochette, A. (1999). Age-related changes in upper extremity performance of elderly people: A longitudinal study. Experimental Gerontology, 34, 393-405.

Dyck, J.L, \& Smither, J.A. (1994). Age differences in computer anxiety: The role of computer experience, gender and education. Journal of Educational Computing Research, 10, 239-248.

Edwards, R., \& Englehardt, K.G. (1989). Microprocessor-based innovations and older individuals: AARP survey results and their implications for service robotics. International Journal of Technology and Aging, 2, 42-55.

Elias, P.K., Elias, M.F., Robbins, M.A., \& Gage, P. (1987). Acquisition of word- 
processing skills by younger, middle-age, and older adults. Psychology And Aging, 2, 340-348.

Fozard, J.L. (1990). Vision and hearing in aging. In Birren, J.E., \& Schaie, K.W. (Eds.), The handbook of the psychology of the aging (pp.150-166). San Diego: Academic Press, Inc.

Galganski, M.E., Fuglevand, A.J., \& Maenoka, R. (1993). Reduced control of motor output in a human hand muscle of elderly subjects during submaximal contractions. Journal of Nuerophysiology, 69, 2108-2115.

Hancock, P.A. (1996). Effects of control order, augmented feedback, input device and practice on tracking performance and perceived workload. Ergonomics, $39,1246-1162$.

Hartley, A.A. (1992). Attention. In Craik, F.I.M., \& Salthouse, T.A. (Eds.), The handbook of aging and cognition. Hillsdale, NJ: Erlbaum.

Harvey, R., \& Peper, E. (1997). Surface electromyography and mouse use position. Ergonomics, 40, 781-789.

Hawthorn, D. (2000). Possible implications of aging for interface designers. Interacting with Computers, 12, 507-528.

Houx, P.J., \& Jolles, J. (1993). Age-related decline of psychomotor speed: Effects of age, brain health, sex and education. Perceptual and Motor Skills, 76, 195-211.

Hutchinson, D., Eastman, C., \& Tirrito, T. (1997). Designing user interfaces for older adults. Educational Gerontology, 23, 497-513.

Jay, G.M., \& Willis, S.L. (1992). Influence of direct computer experience on older adults' attitudes toward computers. Journal of Gerontology, 47, P250-P257.

Karat, J., McDonald, J.E., \& Anderson, M. (1986). A comparison of menu selection techniques: Touch panel, mouse and keyboard. International Journal of ManMachine Studies, 25, 73-88.

Kelley, C.L., Morrell, R.W., Park, D.C., \& Mayhorn, C.B. (1999). Predictors of electronic bulletin board system use in older adults. Educational Gerontology, 25, 19-35.

Kerschner, P.A., \& Hart, K.C. (1984). The aged user and technology. In Dunkle, R.E., Haug, M.R., \& Rosenberg, M. (Eds.), Communications technology and the elderly (pp.135-144). New York: Springer Publishing Company. 
Laux, Lila. A. (2001). Aging, communication and interface design. In Charness, N., Park, D.S., \& Sabel, B.A. (Eds.), Communication, technology and aging: opportunities and challenges for the future (pp153-168). New York: Springer Publishing Co.

Light, K.E., \& Spirduso, W.W (1990). Effects of aging on the movement complexity factor of response programming. Journal of Gerontology, 3-P107-P109.

Marquie, J.C., Thon, B., \& Baracat, B. (1994). Age influences on attitudes of office workers faced with new computer technologies. Applied Ergonomics, 25, 130142 .

Newburger, E.C. (2001). Home computers and Internet use in the United States: August 2001 U.S. Census Bureau: U.S. Census Department of Commerce. (CPR Series P23, No. 207)

Owsley, C., Sekular, R., \& Siemsen, D. (1983). Contrast sensitivity throughout adulthood. Vision Research, 23, 689-699.

Sears, A., \& Shneiderman, B. (1991). High precision touchscreens: Design strategies and comparisons with a mouse. International Journal of ManMachine Studies, 34, 593-613.

Smith, C.D., Umberger, G.H., Manning, E.L., Slevin, J.T., Wekstein, D.R., Schmitt, F.A., et al. (1999). Critical decline in fine motor hand movements in human aging. Neurology, 53, 1458-1461.

Smith, M.W., Sharit, J., \& Czaja, S.J. (1999). Aging, motor control, and the performance of computer mouse tasks. Human Factors, 41, 389-396.

Soukoreff, R.W., \& MacKenzie, I.S. (1995). Generalized Fitts' Law Model Builder. CHI '95 Proceedings Interactive Poster. Retrieved April, 102002 from http://www.acm.org/sigchi/chi95/Electronic/documnts/intpost/rws_bdy.htm

Starr, C. (1999). The graying of America. The Topeka Capitol Journal, November 26, 1999. Retrieved April, 3 2002, from http://www.cjonline.com/stories/112699/new graying.shtml

Stubbs, N.B., Fernandez, J.E., \& Glenn, W.M., (1993). Normative data on joint ranges of motion of 25- to 45-year-old males. International journal of industrialergonomics, 12, 113-114.

U.S. Census Bureau. (2000). Projections of the total resident population by 5-year age 
groups (Publication No. NP-T3-A). Washington, DC: U.S. Department of Commerce.

Whisenand, T.G., \& Emurian, H.H. (1999). Analysis of cursor movements with a mouse. Computers in Human Behavior, 15, 85-103.

Zandri, E., \& Charness, N. (1989). Training older and younger adults to use software. Educational Gerontology, 15, 615-631. 
Effect of Input Device on Movement Time and Error

Appendix A

Human Subjects-Institutional Review Board Approval Letter 


\section{Appendix B \\ Participant Consent Form \\ Agreement to Participate in Research}

Responsible Investigator: Melissa Marie Alvarado

Title of Protocol: Effects of Dexterity and Input Device on Computer Task Performance in Adults Age 65 and Older

1. You have been asked to participate in a research study investigating your performance in terms of movement time and error count with three different computer input devices: mouse, trackball, graphics tablet with digital pen.

2. You will be asked to answer some questions regarding your age, handedness, and physical limitations, you will then be given a test of manual dexterity, and finally you will be asked to perform a series of drag-and-drop and point-and-click tasks using a mouse, a trackball, and a graphics tablet with digital pen in the computer lab in the Senior Center at The City of Mountain View. You will be involved in the experiment for approximately one hour.

3. You may experience temporary physical fatigue or discomfort in your hands, wrists or arms during the course of the experiment due to the number of trials you will perform with the computer input devices. In an attempt to prevent any onset of temporary physical fatigue or discomfort, you will be given rest periods between tasks. You may experience embarrassment if you are not able to use the devices at a level you feel you should. It should be noted however, that there exists no correct or incorrect level of performance expected by the investigator.

4. Although you may not benefit directly from participating in this experiment, you may indirectly experience a feeling of reward from being of help to research. In addition, your exposure to potentially new devices during this experiment may be considered another indirect benefit of your participation in this experiment.

5. There are no alternatives to the procedures for this experiment.

6. Although the results of this study may be published, no information that could identify you will be included.

7. There is no compensation for your participation in this experiment.

8. Questions about this research may be addressed to Melissa Alvarado, (415) 235-5336. Complaints about the research may be presented to Dr. Louis E. Freund, ISE Department Chair, (408) 924-3890. Questions about research subjects' rights or research-related 
injury may be presented to Nabil Ibrahim, Ph.D., Associate Vice President, Graduate Studies and Research, at (408) 924-2480.

9. No service of any kind, to which you are otherwise entitled, will be lost or jeopardized if you choose to "not participate" in the study.

10. Your consent is being given voluntarily. You may refuse to participate in the entire study or in any part of the study. If you decide to participate in the study, you are free to withdraw at any time without any negative effect on your relations with San Jose State University or with any other participating institutions or agencies.

11. At the time that you sign this consent form, you will receive a copy of it for your records, signed and dated by the investigator.

- The signature of the participant on this document indicates agreement to participate in the study.

- The signature of the investigator on this document indicates agreement to include the above named participant in the research and attestation that the participant has been fully informed of his or her rights. 
Appendix C

\section{Demographics Questionnaire / Purdue Pegboard Test data}

\section{Age}

\section{Gender:}

Male

Female

\section{Declared Mousing Hand:}

Right

$$
\text { Left }
$$

\section{Length of experience with the following over lifetime:}

(years, months)

Windows-based computer system:

Mouse:

Trackball:

Graphics tablet with digital pen:

Physical limitations (of the hand or arm; e.g. arthritis, recent injuries or diseases)

\section{Purdue Pegboard Test Data}

Right Hand Left Hand Both hands

Right + Left + Both Hands (sum, not tested) Assembly 
Effect of Input Device on Movement Time and Error

Appendix D

Purdue Pegboard Manual 


\section{QUICK REFERENCE GUIDE FOR THE PURDUE PEGBOARD \#32020}

\begin{tabular}{|lr|}
\hline \multicolumn{2}{|c|}{ CONTENTS } \\
PREFACE & \\
Introduction & 1 \\
Application & 1 \\
ADMINISTRATION & 1 \\
Test Batteries and Timing & 1 \\
Equipment Required & 2 \\
TEST PROCEDURES & 2 \\
General Instructions & 2 \\
Right Hand & 2 \\
Left Hand & 2 \\
Both Hands & 3 \\
Right + Left + Both & 3 \\
Assembly & 4 \\
INTERPRETATION AND SCORING OF DATA & 4 \\
Types of Interpretation Scales & 5 \\
Normative Data and Scoring & 5 \\
Using New Interpretation Charts & 5 \\
REPLACEMENT PARTS AND REORDERING & 6 \\
INFORMATION & 6 \\
REFERENCES & 7 \\
FIGURE 1. INTERPRETATION CHART & \\
EXAMPLE & 7 \\
FIGURE 2A-H. Occupational Areas & $8-15$ \\
\hline
\end{tabular}




\section{PrefaCe}

\section{Introduction}

Joseph Tiffin, Ph.D., Industrial Psychologist, Purdue University (1948), first developed the Purdue Pegboard for the selection of employees for industrial jobs. Today the board has various applications. This Quick Reference Guide focuses solely on Tiffin's original test procedures and test norms, which are presented in Tables 8-15 within Appendix A of the Purdue Pegboard Manual (PPM).

In addition to the original test, test procedures and data appear in PPM for the following applications:

- Indicating the presence and laterality of brain damage (Costa et. al. 1963);

- Discriminating children with learning disabilities (Kane and Gill 1972);

- Assessing performance of schoolchildren with neurologically based learning disabilities (Gardner and Broman 1979);

- Assessing candidates for vocational rehabilitation (Hamm and Curtis 1980);

- Assessing the performance of dyslexic subjects (Leslie, Davidson, and Batey 1985).

\section{Application}

The Purdue Pegboard aids in the selection and rehabilitation of employees for various types of manual labor by measuring 2 types of dexterity:

1. Gross movements of the fingers, hands, and arms.

2. Fine fingertip dexterity necessary in assembly tasks.

The Purdue Pegboard can be used for many testing applications, such as Physical Therapy, Occupational Therapy, Vocational Evaluation, and Preemployment Screening. Other applications for the test can be found by doing a bibliography search.
Physical and Occupational Therapists use the Purdue Pegboard for injury rehabilitation. They use the test as a tool to obtain baseline data on a patient. They also use it to document patient progress and/or degree of disability.

Vocational Evaluators use the Purdue Pegboard to determine a subject's ability and aptitude for certain work-related applications and for recommending placement in jobs that require manual dexterity. The Purdue Pegboard is also used to develop a specific training program that will give an individual the skills to complete a job task that requires manual dexterity.

Human Resource Directors and Temporary Staffing Agencies use the Purdue Pegboard as a pre-employment screening and selection tool. An applicant's performance on the Purdue Pegboard can indicate their ability to perform in a job/task that requires manual dexterity. Note: It is strongly recommended that the testing organization shows a correlation between a subject's performance on the Purdue Pegboard and a subject's performance in the specific job task. This may be accomplished by testing subjects currently working in a specific job task who are high performers and low performers. Then test the same subjects using the Purdue Pegboard. The high performers should score higher on the Purdue Pegboard than the low performers.

\section{ADMINISTRATION}

Before administering the Purdue Peghoard Test, the test administrator is advised to carefully read this section of the manual. As with any standardized test, it is important to follow the directions very closely. If the Purdue Pegboard Test is to be used as a basis for employee selection, the test must be administered to all applicants according to the standardized test procedure. If the test is not given identically, irrelevant factors may affect test scores. In order 
to reduce the variability among test administrators, specific details regarding the arrangement of materials and the testing procedures are presented below.

Practice the administration of the Purdue Pegboard before conducting a test on a subject. The amount of practice needed in order to become comfortable with the testing process is dependent upon the test administrator's previous testing experience. The test administrator should practice the Purdue Pegboard until he or she is able to perform each of the tests at an average speed for demonstration purposes. Note: The test administrator will be demonstrating to the test subject what is expected of him or her before each test.

\section{Test Batteries and Timing}

The test administrator will compile 5 separate scores from the complete test procedure, one for each test battery:

1. Right hand (30 seconds)

2. Left hand ( 30 seconds)

3. Both hands ( 30 seconds)

4. Right + Left + Both hands (Note: This is not an actual test; it is a mathematical sum calculation.)

5. Assembly (60 seconds)

The test batteries should be done in this consecutive order, unless the subject is left-handed, where test batteries 1 and 2 are reversed: Left Hand first and then Right Hand. Three test trials are highly recommended: the more trials administered, the more test score reliability. Note: The test is well suited for either group or individual testing.

\section{Equipment Required}

The following equipment and supplies are required to ensure that the Lafayette Instrument Purdue Pegboard Test is a consistent, standardized test:

1. Purdue Pegboard Test (Model \#32020)
a. Instruction Manual
b. 1 Test Board
c. Pins, Collars, Washers
d. Score Sheets

2. At least one testing table approximately 30 inches tall. Note: The subject must be seated throughout the administration of the test.

3. Stopwatch or clock that reads in seconds.

\section{TEST PROCEDURES}

\section{General Instructions}

The subject should be comfortably seated at the testing table directly in front of the Purdue Pegboard, which is placed on the table with the row of cups (under the nameplate) at the top of the board. The far right and far left cups should have 25 pins in each to equal a total of 50 pins. For right-handed subjects, the cup to the right of center should have 20 collars and the cup to the left of center should have 40 washers. If the subject is left-handed, the collar and washer locations should be on the reverse side of center. The following directions are for single subject testing and should be appropriately modified for group testing.

When the subject(s) is seated and ready to begin, say:

"This is a test to see how quickly and accurately you can work with your hands. Before you begin each battery of the test, you will be told what to do and then you will have an opportunity to practice. Be sure you understand exactly what to do."

\section{Right Hand (30 seconds)}

Begin by saying and demonstrating: 
"Pick up one pin at a time with your right hand from the right-handed cup. Starting with the top hole, place each pin in the right-hand row. (Leave the pin used for demonstration in the hole.) Now you may insert a few pins for practice. If during the testing time you drop a pin, do not stop to pick it up. Simply continue by picking another pin out of the cup."

Correct any errors made in placing the pins and answer any questions. When the subject has inserted three or four pins and appears to understand the operation, say:

"Stop. Now take out the practice pins, and put them back into the right-hand cup."

After the subject completes this task, say:

“When I say 'Begin,' place as many pins as possible in the right-hand row, starting with the top hole. Work as rapidly as you can until I say 'Stop."'

“Are you ready? Begin.”

Start timing when you say "Begin." At the end of exactly 30 seconds, say:

"Stop."

Count the number of pins inserted and record the Right Hand score. This is the total number of pins the subject placed with the right hand. Leave the pins in the holes.

\section{Left Hand (30 seconds)}

Begin by saying:

"Pick up one pin at a time with your left hand from the left-hand cup. Place each pin in the lefthand row, starting with the top hole. You may insert a few pins for practice."
When the subject has inserted three or four pins and appears to understand the operation, say:

"Stop. Now take out the practice pins, and put them back into the left-hand cup."

After the subject completes this task, say:

“When I say 'Begin,' place as many pins as possible in the left-hand row, starting with the top hole. Work as rapidly as you can until I say 'Stop.'”

"Are you ready? Begin."

Start timing when you say "Begin." At the end of exactly 30 seconds, say:

\section{"Stop."}

Count the number of pins inserted and record the Left Hand score. This is the total number of pins the subject placed with the left hand. Leave the pins in the holes. After the Right Hand and Left. Hand test batteries have been completed, the subject returns all pins to their proper cups.

\section{Both Hands (30 seconds)}

This test battery tests both hands working together. Begin by saying:

"For this part of the test, you will use both hands at the same time. Pick up a pin from the right-hand cup with your right hand, and at the same time pick up a pin from the left-hand cup with your left hand. Then place the pins down the rows. Begin with the top hole of both rows. (Demonstrate. Then replace the pins used for demonstration.) Now you may insert a few pins with both hands for practice."

After the subject has three or four pairs of practice pins correctly inserted, say: 
"Stop. Take out the practice pins, and put them back in the proper cups."

Then say:

“When I say 'Begin,' place as many pins as possible with both hands, starting with the top hole of both rows. Work as rapidly as you can, until I say 'Stop.'”

"Are you ready? Begin."

Start timing when you say "Begin." At the end of exactly 30 seconds, say:

“Stop.”

Count the number of pairs of pins inserted (not the total number of pins), and record the score. The subject then returns the pins to the proper cups.

\section{Right + Left + Both (Sum of scores)}

This score is not based on a separate test; it is obtained from combining the test scores of the previous three test batteries. Add the scores recorded for Right Hand, Left Hand, and Both Hands; this is the score that you record for $\mathrm{R}+\mathrm{L}$ + Both.

This score does not have to be recorded during the actual testing period. The Assembly test may begin immediately after the Both Hands score is recorded.

\section{Assembly (1 minute)}

This test battery consists of assembling pins, collars, and washers. Demonstrate the following operations while saying:

"Pick up one pin from the right-hand cup with your right hand. While you are placing it in the top hole in the right-hand row, pick up a washer with your left hand. As soon as the pin has been placed, drop the washer over the pin. While the washer is being placed over the pin with your left hand, pick up a collar with your right hand. While the collar is being dropped over the pin, pick up another washer with your left hand and drop it over the collar. This completes the first 'assembly,' consisting of a pin, a washer, a collar, and a washer. While the final washer for the first assembly is being placed with your left hand, start the second assembly immediately by picking up another pin with your right hand. Place it in the next hole, drop a washer over it with your left hand, and so on, completing another assembly. Now, take a moment to try a few practice assemblies."

Emphasize that both hands should be operating at all times: one picking up a pin, one a washer, one a collar, and so on.

The subject should be allowed to make four or five complete assemblies before the test is begun to make certain the subject fully understands the "alternating" procedure. The subject must keep both hands moving at the same time. If he or she fails to do this, the administrator should give further instructions. Note: If the subject is left-handed, the washer and collar locations in the cups are switched. The subject begins by picking up the pin with his/her left hand, the washer with his/her right hand, the collar with his/her left hand, another washer with his/her right hand and so on through all assemblies.

After the subject has practiced the assemblies, say:

"Stop. Now return the pins, collars, and washers to their proper cups."

Then say:

'When I say 'Begin,' make as many assemblies as possible, beginning with the top hole. Work quickly until I say 'Stop.'”

Start timing when you say "Begin." After exactly 1 minute (60 seconds), say:

"Stop." 
Count the number of parts assembled and record the Assembly score. Since there are four parts in each assembly, if the subject made eight complete assemblies, the score is 8 multiplied by 4 (parts), or 32. Beyond completed assemblies, if there are additional parts properly placed at the end of the minute, they are also added to the Assembly score. For example, if there is another pin and first washer, in addition to those 2 parts, the score is 32 +2 , or 34 . After the test administrator records this score, the subject should return the pins, collars, and washers to the proper cups.

\section{INTERPRETATION AND SCORING}

\section{Types of Interpretation Scales}

There are several ways to evaluate the subject and his/her raw scores. Note: It is assumed that the data represents a normal distribution. These three types of interpretation scales follow:

1. Percentile scale

2. Standard scale

3. Verbal scale

\section{Percentile Scale}

Use the percentile scale when a subject's score must be interpreted in terms of a percent of the normal population surpassed by the subject. For example, if the subject's score is at the midpoint ( 50 percentile on the scale), it means that the score made by a subject was better than 50 percent of the normative population. Other percentile points are interpreted in a similar fashion. The instructions for scoring appear in the Normative Data and Scoring section.

\section{Standard Scale}

The standard scale is a statistical analysis of a subject's score. It is derived from a normal frequency curve or bell-shaped curve. The Mean, which is the arithmetic average, and Standard
Deviation (S.D.) numbers are provided in PPM as well as in the New Interpretation Charts, which are labeled as Figure $2(\mathrm{~A}-\mathrm{H})$ on pages 8-15. Generally, 68 percent of scores fall between -1 and +1 S.D.; 95 percent between -2 and +2 S.D.; 99.70 percent between -3 and +3 S.D. There are a very small percentage of scores that fall either above or below 3 S.D. from the Mean. The instructions for scoring appear in the Using New Interpretation Charts section on page 6 .

\section{Verbal Scale}

The verbal scale is merely a scale of broad categories. Thus, a subject should be described as having excellent ability when his/her score falls higher than 2 S.D. above the Mean. When a subject's score falls between 1 S.D. and 2 S.D. above the Mean, they should be described as having high-average ability. A subject described as having average ability would have a score that falls within the range of 1 S.D. above and below the Mean. A low-average subject would have a score that falls between 1 S.D. and 2 S.D. below the Mean. A subject should be described as having poor ability when his or her score falls under 2 S.D. below the Mean. The instructions for scoring appear in the Using New Interpretation Charts section on page 6 .

\section{Normative Data and Scoring}

The PPM is the source of the following statistical data. Percentile rank tables in Appendix A (Tables 8 through 15) address each occupation area so the test administrator may plot the subject's raw scores and convert them into a percentile score that can be recorded. This will enable the test administrator to conduct subject score comparisons with the normative population.

To utilize the percentile tables, identify the appropriate table ( 8 through 15 ) for the occupation area that best describes the subject. Locate the subject's raw score or the average of 3 trials for each test battery under the corresponding heading 
(i.e., Right Hand, Left Hand) within the percentile box. Draw a line from that raw score across to the left or right outside edge of the box to where the percentile scores are located (1-99). This will give you the converted score, from raw scores to percentiles. Record this number on the score sheet. For example, if a subject's percentile score is " 30 ," this means that the subject performed better than 30 percent of the normative population. Note: If the subject's preferred hand is the Left Hand, the Left Hand score should be looked up under the Right Hand column heading on these tables.

The Mean and Standard Deviations (S.D.) have also been provided at the bottom of each percentile table. Note: The Mean does not always represent 50 percentile, this may be attributed to sampling size and/or sampling error. The differences between the mean and 50 percentile do not seem to be significant. The Mean and S.D. can be used to plot the subject's score on a bell-shaped curve and interpret using the standard scale or verbal scale. The instructions for using these scales appear in the next section.

\section{Using New Interpretation Charts}

All of the possible scores that fall into the range of data provided in Appendix A have been analyzed and plotted, using the "Standard Scale" (Mean and S.D.). The scores are presented in the form of a color-coded bar graph. The bar graph represents a normal distribution or bell curve, but the actual curve is not shown. The colors indicate the gradations of performance based on the "Verbal Scale." Note: This is illustrated in Figure 1 on page 7.

To utilize the new interpretation charts, identify the appropriate chart for the occupational area that best describes the subject. Refer to the proper bar graph for data regarding each test battery. Locate the subject's raw score or the average of 3 trials. Evaluate the score using the verbal scale, the standard scale, or both. Look at the top of the bar graph for the verbal score. The sections are color coded for convenience. The subject's raw score can also be used to determine how many S.D. above or below the Mean the score falls. Read the S.D. from the outside inward. Notice the arrows in the example chart (Figure 1) on the next page.

Using the data in Figure 1, if the raw score is 14, then evaluate the subject's score as 2 S.D. below the Mean. The score is Low-average compared to the normative population. If the raw score is 19 , then the score falls within 1 S.D. above the Mean, which is also Average, compared to the normative population. All raw scores are evaluated in this manner. Note: Customers using the Lafayette Purdue Pegboard have reported a decrease in subject scores in recent years. Therefore, the scores may appear lower as compared to the original normative data.

\section{REPLACEMENT PARTS AND REORDERING INFORMATION}

We, at Lafayette Instrument Company, continue our service after the sale by offering the following replacement parts for the Purdue Pegboard:

Pins, Collars, \& Washers .....\# 32103

Manual.......................\# 32108

Score Sheets..................\# 32107

We can be contacted between 8:00 a.m. - 5:00 p.m. Monday through Friday for pricing and ordering.

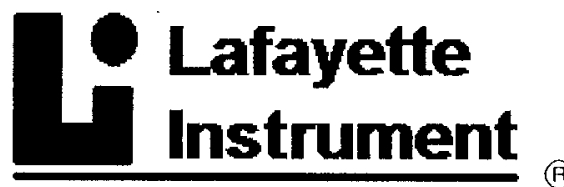
P. O. Box 5729 - 3700 Sagamore Pkwy N Lafayette, IN 47903 USA Phone 765-423-1505, Fax 765-423-4111 USA Toll Free 800-428-7545 ext. 207 e-mail rehabolafayeteinstrument com http://www.lafayetteinstrument.com 


\section{REFERENCES}

Costa, L. D., H. G.Vaughan, Jr., E. Levita, and N. Farber. 1963. Purdue Pegboard as a predictor of the presence and laterality of cerebral lesions. Journal of Consulting Psychology 27: 133-137.

Gardner, R. A., and M. Broman. 1979. The Purdue Pegboard: Normative data on 1,334 schoolchildren. Journal of Clinical Psychology 1: 156-162.

Hamm, N. H., and D. Curtis. 1980. Normative data for the Purdue Pegboard on a sample of adult candidates for vocational rehabilitation. Perceptual and Motor Skills 50: 309-310.

Kane, J., and R. P. Gill. 1972. Implications of the Purdue Pegboard as a screening device. Journal of Learning Disabilities 547: 36-40.

Lafayette Instrument Company (LIC). 1985. Instructions and normative data for Model 32020, Purdue Pegboard. Lafayette, IN: LIC.

Leslie, S. C., R. J. Davison, and O. B. Batey. 1985. Purdue Pegboard performance of disabled and normal readers: Unimanual versus bimanual differences. Brain and Language 24: 359-369.

\section{Figure I INTERPRETATION CHART EXAMPLE Male \& Female Applicants for Production Work $(n=454)$}

Right Hand:

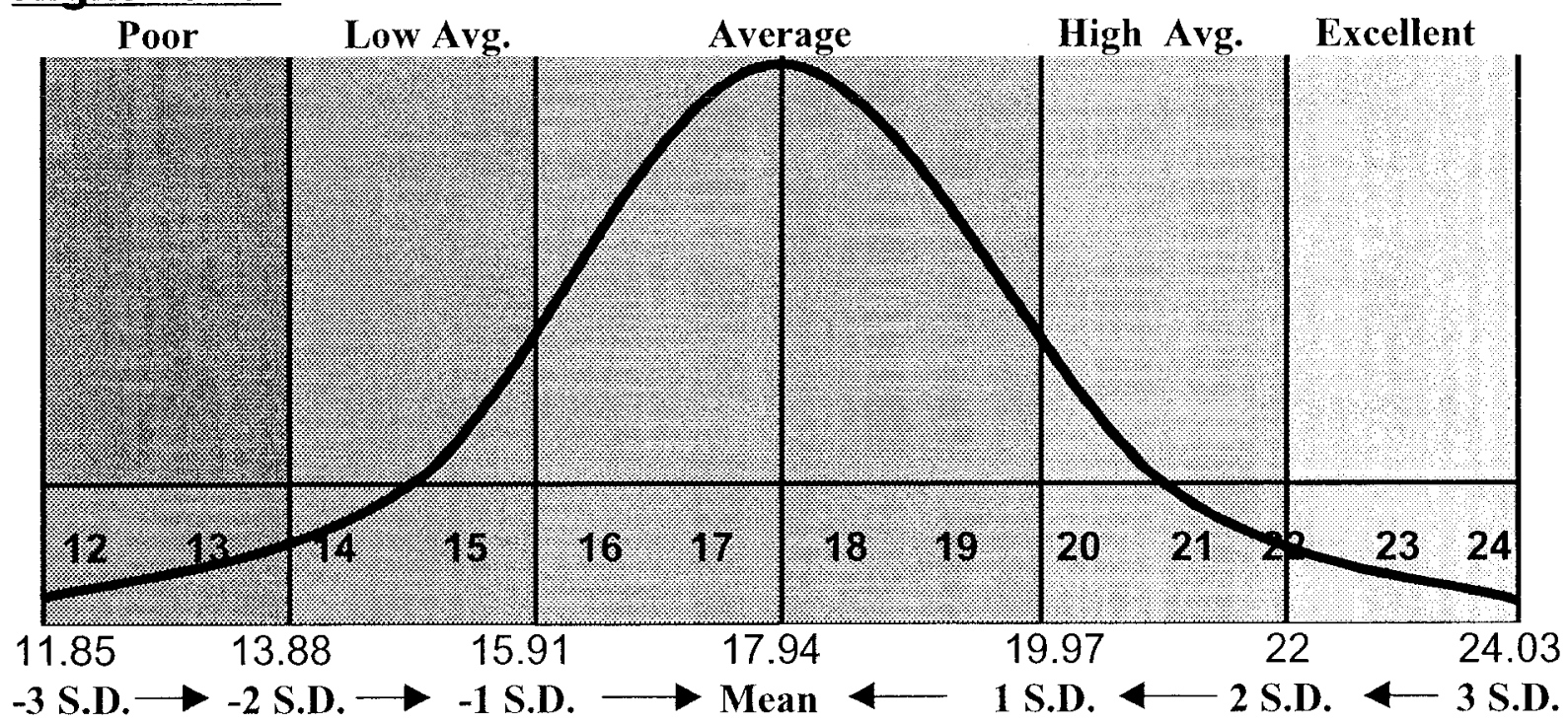


Appendix D

\section{Participant Instructions}

Please read these instructions completely and notify the experimenter when you are finished:

You will be performing two types of tasks using the computer and the mouse, trackball, and graphics tablet. The first task is a point-and-click task and the second is a dragand-drop task. Your movement time to complete the trials in addition to error count will be recorded by the computer so you should work as quickly and accurately as possible.

In the point-and-click task you will begin each trial by depressing and releasing the mouse button once, which will change the start box into a cross hair cursor. You will then move the cursor to the target as rapidly as possible and depress the mouse button once to complete the trial. If you press the button and you are not on the target, you will hear a beep and you must move the cursor onto the target and push the button again. You will complete 2 sets of 32 trials (64 trials) for the point-and-click task, each with the target at different locations on the screen. You will perform this task with each of the three input devices.

After the point-and-click task, you will be allowed a 2-minute rest period to relax and stretch before next trial block of the experiment begins.

In the drag-and-drop task you will begin each trial by depressing and holding down the mouse button (when you press the button down the start box will change into a cross hair cursor). With the mouse button depressed, you will then move the cursor to the target as rapidly as possible and release the mouse button to complete the trial. If you release the button and you are not on the target, you will hear a beep and you must depress the button, move the cursor onto the target and release the button again. You will complete 2 sets of 32 trials (64 trials) for the drag-and-drop task, each with the target at different locations on the screen. You will perform this task with each of the three input devices.

The experimenter will demonstrate each of the two tasks for you. After the demonstration, you will perform a practice session with each of the tasks before the experiment begins. If you have any questions regarding the tasks at this time, after the demonstration or after the practice interval, the experimenter will answer them for you

Remember that you should complete the tasks as quickly and as accurately as possible. Please notify the instructor when you are finished reading these instructions. 